\title{
REACH-SCALE CONTRIBUTIONS OF ROAD-SURFACE SEDIMENT TO THE HONNA RIVER, HAIDA GWAII, B.C. \\ by
}

\author{
David A. Reid \\ B.A., The University of British Columbia, 2011 \\ A THESIS SUBMITTED IN PARTIAL FULFILLMENT OF \\ THE REQUIREMENTS FOR THE DEGREE OF \\ MASTER OF SCIENCE \\ in \\ THE FACULTY OF GRADUATE AND POSTDOCTORAL STUDIES \\ (Geography) \\ THE UNIVERSITY OF BRITISH COLUMBIA \\ (Vancouver)
}

August 2014

(C) David A. Reid, 2014 


\begin{abstract}
Unpaved resource road surfaces may act as dominant sources of fine sediment to streams, yet their relative contribution to in-channel sediment yields remains poorly understood. Significant quantities of road-surface sediment have been observed entering the Honna River, B.C, a $5^{\text {th }}$ order channel located is close proximity to a major, intensively used resource road. In September 2012, a reach of the Honna River was selected for measurement and instrumentation to compile a sediment balance with a focus on the relative importance of road surface sediment over an annual scale. An additional four months of suspended-sediment data were collected at 6 locations in the reach to determine spatial and temporal dynamics of suspended-sediment concentrations and yields. Road surface sediment contributed $19 \% \pm 6 \%$ of the total annual fine sediment balance for the reach, even though only $\sim 20 \%$ of the road area was an effective sediment source. Persistent clockwise hysteresis was observed in the SSC-discharge relation in the main river channel, but was not as apparent in ditch drainage channels. As a proportion of total input, road surface material ranged from $0.5 \%$ to $15 \%$ during dry conditions from April to the end of September, and from 5\% to $70 \%$ in the wet season from October to the end of March. Road surface material appears likely to settle on the river channel bed during low flow conditions, but only temporarily, and in small quantities relative to natural sediment sources. Additional research is needed to assess basin-scale contributions of road surface sediment.
\end{abstract}




\section{Preface}

This thesis is based on field data collected in collaboration with the Provincial Ministry of Forests, Lands and Natural Resource Operations, Coast Region, and under the supervision of Dr. M. Hassan (UBC Geography) and Dr. W. Floyd (MFLNRO). With the exception of precipitation and vehicle traffic monitoring equipment installed by previous graduate student Elizabeth Baird, all implementation of field instrumentation and collection of field data was undertaken by individuals aforementioned, with two weeks of field assistance from undergraduate students. Laboratory sample processing took place partly at the MFLNRO Haida Gwaii district office, and partly at the UBC Vancouver campus. Novel research methods were applied to this project in the use of a reachscale sediment balance to examine contributions of road surface sediment to a stream.

I undertook all laboratory sample processing, analysis of data, and writing of the thesis manuscript. 


\section{Table of Contents}

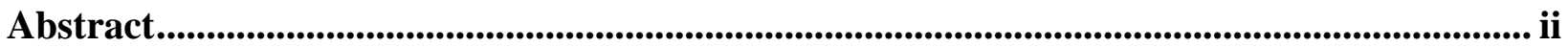

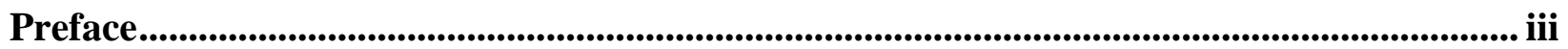

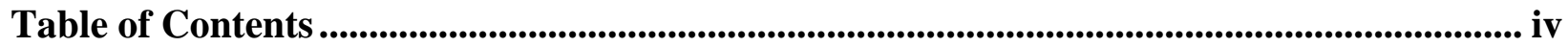

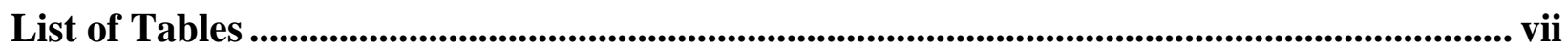

List of Figures.................................................................................................................................................... viii

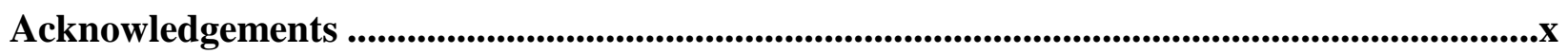

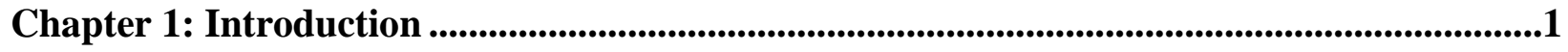

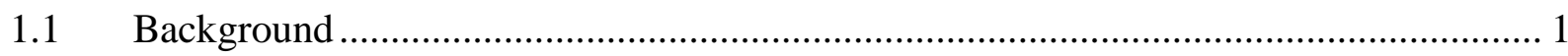

1.2 Production of sediment on road surfaces ....................................................... 2

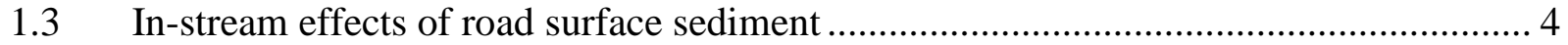

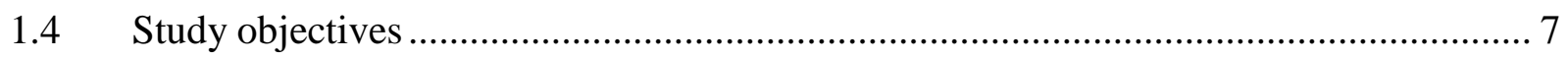

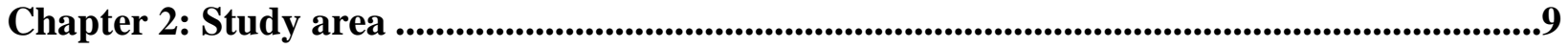

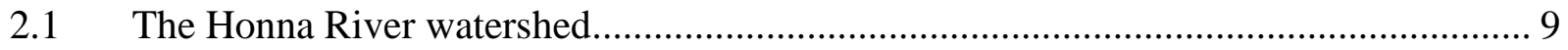

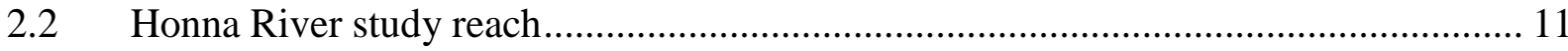

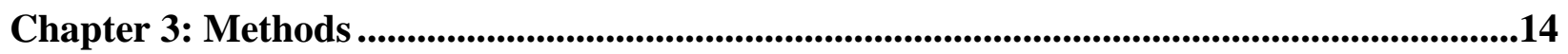

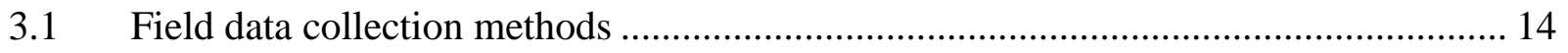

3.1.1 Collection of turbidity and discharge data ................................................... 14

3.1.2 Sediment input from bank retreat ........................................................... 15

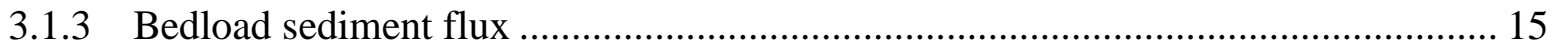

3.1.4 Measured change in suspended and bedload sediment storage ........................... 16

3.1.5 Additional field measurements .............................................................. 17 
3.2 Reach scale sediment balance formulation ..................................................... 18

3.3 Determination of reach sediment balance components ........................................ 20

3.3.1 Suspended sediment upstream inputs, road surface inputs, and reach outputs........ 20

3.3.1.1 Suspended sediment flux uncertainties ................................................. 23

3.3.2 Estimation of sediment input from bank erosion ........................................... 26

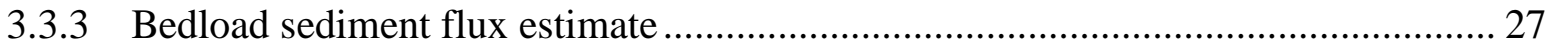

3.3.4 Change in channel bed storage ............................................................. 28

3.4 Suspended-sediment dynamics and SSC-discharge hysteresis ............................... 29

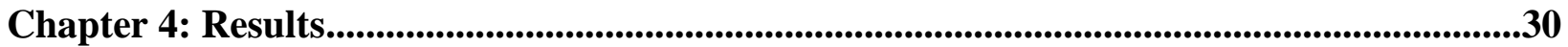

4.1 Summary of hydrological and environmental characteristics during study period ...... 30

4.2 Event scale suspended-sediment concentration dynamics .................................... 32

4.3 Reach scale sediment balance for 12 month period - Sept 2012 to Sept 2013 ........... 38

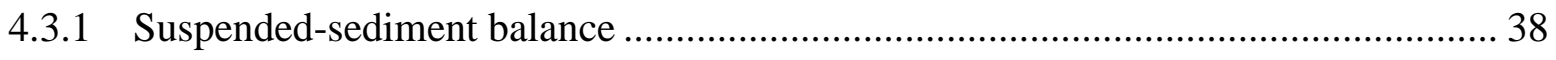

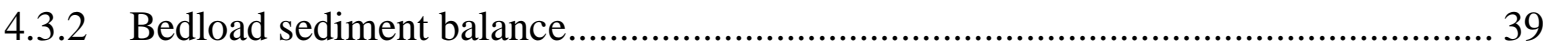

4.3.3 Measured change in sediment storage ..................................................... 41

4.4 Spatial and temporal patterns of suspended sediment dynamics over 16 months ....... 42

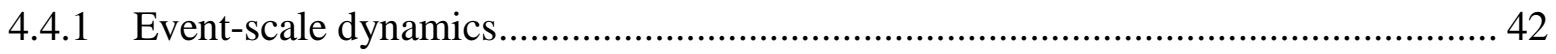

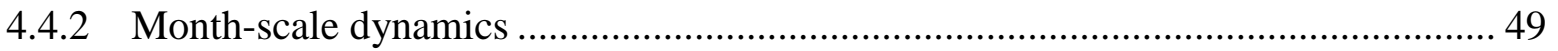

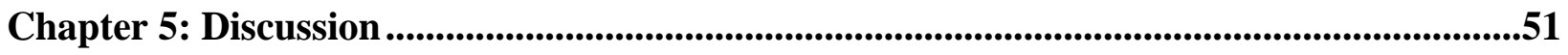

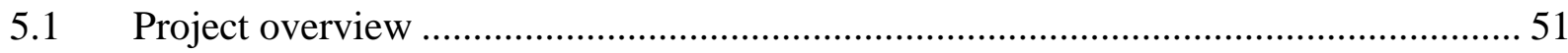

5.2 Road surface material as a reach-scale sediment balance component ...................... 51

5.3 Effective contributing road area and hydrogeomorphic connectivity...................... 54

$5.4 \quad$ Availability and dynamics of suspended-sediment........................................... 55 
5.5 Temporal dynamics in road surface sediment contributions ................................. 58

5.6 Implications of findings for land managers ................................................. 59

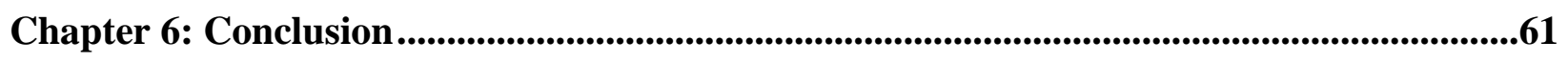

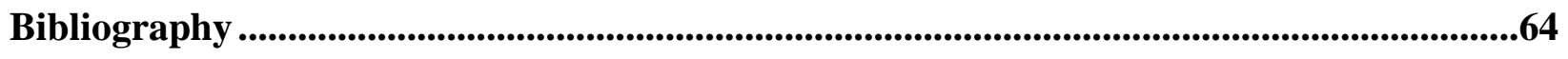




\section{List of Tables}

Table 1: Summary of studies examining in-stream effects of road surface sediment ................. 6

Table 2: Honna River Basin and study reach physical characteristics .................................. 13

Table 3: Suspended-sediment yield error components and terms ...................................... 21

Table 4: Bedload tracer stone characteristics and recovery statistics .................................. 41 


\section{List of Figures}

Figure 1: Honna River basin and surrounding area..................................10

Figure 2: Honna River study reach and QC Main forest road with road contributing area

highlighted. 12

Figure 3: SSC-turbidity relations for suspended material in-channel and from road surface in the Honna River basin. 22

Figure 4: Instantaneous discharge (A), daily rainfall totals (B), and daily traffic totals (C) observed in the study reach over 16 month period. 31

Figure 5: Grain size distribution (GSD) of suspended material found 32

Figure 6: Relations between SSC and discharge during events on November $21^{\text {st }} 2012$ and August $18^{\text {th }}$ 2013, at the reach outlet (A,B), reach inlet (C,D), and DD3 ditch drainage channel $(\mathrm{D}, \mathrm{E})$. Arrows indicate direction of hysteresis. 35

Figure 7: A: Comparison of $\mathrm{H}$ value over time in the main channel and in DD3 ditch drainage. B: Relation between discharge and $\mathrm{H}$ value in the main channel and DD3 ditch drainage............. 36

Figure 8: Cumulative exceedance of suspended sediment concentrations at the ..................... 37

Figure 9: Components of reach-scale fine sediment balance, in tons.................................... 38

Figure 10: Relation between scaled particle distance and scaled ......................................... 40

Figure 11: Availability of fine sediment on the reach channel bed during ............................. 41

Figure 12: Cumulative yields of water and sediment at the upstream reach ........................... 43

Figure 13: Plots of net sediment gains and losses per event, and per-event total yields of sediment at the reach inlet, outlet, and ditch drainage channels. 45 
Figure 14: A: comparison of per-event collective reach input vs output. B: Comparison of change in net sediment storage vs reach output. C: Ratio of inputs/outputs vs total sediment flux from the reach.

Figure 15: Road surface material as a proportion of total inputs to the reach over the 16 month period.

Figure 16: A: month-scale net sediment gains and losses. B: Monthly sediment flux at reach inlet, outlet, and from collective ditch drainages. C: Road surface material as a proportion of all inputs during each month. D: Monthly rainfall totals. E: Mean monthly discharge 50 


\section{Acknowledgements}

I thank my supervisors Dr. Marwan Hassan and Dr. William Floyd for their guidance, inspiration, and support, and for the opportunity to undertake a project in one of the best field sites a student could hope to work in. Their oversight has undoubtedly improved my skill as a researcher, and has inspired me to pursue further education in the field. I thank the British Columbia provincial Ministry of Forests, Lands and Natural Resource Operations and Mitacs Accelerate program for their financial support, and Dr. Lawrence Meadows for assistance in preparing grant applications. I am deeply grateful for the logistical assistance provided Larry Duke, Alanah Mountifield, Marlene van Reishote, Leonard Munt and everyone else at the Haida Gwaii district office, and I thank Jordan Pryce for fieldwork help and being a magnet for all of the bugs on Graham Island. I am also grateful for assistance surrounding administrative issues from Sandy Lapsky, Suzanne Lawrence, and all of the UBC Geography staff.

I thank my family and friends for their words of support and encouragement, especially my parents, who undoubtedly had to endure the bulk of my thesis-related complaints. 


\section{Chapter 1: Introduction}

\subsection{Background}

Forested streams are sensitive environments that form important habitat for numerous aquatic species, and are the primary source of drinking water for many communities worldwide. The dynamics of sediment and in-channel wood of these systems shape their morphology, channel boundary conditions and dimensions (Dietrich \& Dunne 1978; Hassan et al. 2005; Church \& Hassan 2005), and ecology (Bruton 1985; Gregory \& Northcote 1993; Wood \& Armitage 1997; Curry \& MacNiell 2004; Ramos-Scharrón \& Macdonald 2007). In stream networks, the sediment load is commonly divided into bedload sediment, transported in contact with the channel bed, and finer sediment which is suspended within the water column (e.g. Hassan et al., 2005). Suspended sediment (SS) is traditionally described as clasts or organic material finer than $0.2 \mathrm{~mm}$ (Gomi et al. 2005), although the threshold grain size between suspended and bed load depends on individual river and sediment characteristics (Walling and Moorehead, 1989). Suspended material often composes the larger proportion of total sediment yield transferred through river systems (Dietrich \& Dunne 1978; Dunne \& Leopold 1978). Although SS occurs naturally in streams and is important for stream health, changes in SS dynamics as a result of land use changes can have significant negative effects on stream ecology by reducing water circulation in gravel substrates (Beschta, 1978; Kondolf, 2000; Kemp et al, 2011) and limiting the quantity of light available for photosynthesis (Bilby, 1985). As particulate matter effectively harbors pathogens, additional suspended sediment may also reduce water quality for human consumption (Gadgil 1998; Marquis 2005). 


\subsection{Production of sediment on road surfaces}

Of particular interest to researchers studying mountain stream water quality is the production and transfer of sediment from resource road surfaces to channels, and the relative importance of this sediment source as a reach scale balance component. Unpaved resource road surfaces, such as those used by the logging industry in the Pacific Northwest of North America, can act as major sources of fine sediment to streams, elevating in-channel concentrations, and potentially reducing water quality (Reid and Dunne, 1984; Bilby et al. 1989; Lane \& Sheridan, 2002). In fact, road surface sediment may be the dominant SS source in forested areas (Reid and Dunne, 1984; Croke et al. 1999) or in regions with no hillslope activity (Bilby et al. 1989), notable given their comparatively small contributing area. Forest road surfaces can be major producers of sediment because they are compacted and unprotected by vegetation and therefore significantly more erodible and impermeable to rainfall than the surrounding landscape (Spinelli \& Marchi 1996; Ziegler \& Giambelluca 1997; Moore \& Wondzell 2005), yet are topped with a non-cohesive, fine material which is easily loosened and transported (Luce \& Black, 1999; van Meerveld et al., 2014). Although road surfaces have been found to contribute the most water and sediment within a road prism, other prism components, such as ditches or road cuts, may also contribute sediment, especially during intense rainfall (Luce and Black, 1999; Croke et al., 2006).

Several factors affect the quantity and texture of fine sediment produced on a road surface. Generally, the texture of transported sediment is fine $(<.004 \mathrm{~mm})$ but greater transport capacities of flow accumulated over long or steep road segments can increase total sediment yields of both suspended-fraction and coarser-textured material, such as sand $>0.25 \mathrm{~mm}$ in diameter (Bilby et al., 1989; Luce and Black, 1999). Even on roads with steep segments, fines can still form the dominant sediment source with at least at least $50 \%$ of transported sediment finer than $0.02 \mathrm{~mm}$ 
(Costantini et al., 1999), suggesting that material delivered from roads is mainly composed of silt and fine sand. Roads surfaced with weak, easily degraded aggregate, or composed of finer particles (silt and fine sand, in particular) produce much greater quantities of sediment than roads surfaced with harder, coarser material. Kockenderfer and Helvey (1987) found that ungravelled, soilsurfaced roads experienced nearly eight times as much soil loss as gravelled roads, and Bilby et al. (1989) observed that, when scaled by traffic volume, secondary forest roads surfaced with local pit-run rock yielded six times as much sediment as mainline roads covered with harder gravel. Positive relations between sediment yield and fining surface material on roads were also observed, with the highest yields emanating from roads surfaced with material more than $20 \%$ silt by mass (Luce and Black, 1999; Costantini et al. 1999; Sugden and Woods, 2007).

Disturbance of road surfaces by vehicle traffic or road maintenance can greatly increase the quantity of sediment produced relative to undisturbed roads. Vehicle traffic breaks down surface aggregates and disturbs armor layers, replenishing supplies of fine, transportable sediment, and the weight of vehicles can force fines in the road bed to the surface through hydraulic piping (Ziegler et al., 2001b, van Meerveld, 2014). Additionally, traffic may cause rutting, channelizing runoff sufficiently to erode road bed material (Foltz, 1996, Ziegler 2001b). For example, Reid and Dunne (1984) found that heavily used roads yielded up to 130 times as much sediment as equivalent abandoned roads, while Bilby et al. (1989) observed that road use accounted for an increase in area-scaled sediment yield by a factor of 2.5 over more lightly used roads. Other studies (Luce and Black, 1999; 2001; Ziegler et al., 2001b; Sugden and Woods, 2007) note that road construction or maintenance activities (grading in particular) can increase the availability of transportable sediment for up to three years following the disturbance. 
The nature of the connection between a road surface and nearby water body controls both the yield and character of the sediment transferred. Sediment leaving a road surface is delivered to streams most effectively if no buffering floodplain exists (such as at a road stream crossing), or if a channelized connection is present between the sediment source and the main stream channel (Duncan et al, 1987; Bilby et al., 1989; Megahan and Ketcheson, 1996; Costantini et al, 1999; Brown et al., 2014). Additionally, the lack of flow competence on road surfaces combined with low water velocities in ditches and drainage channels leads to the deposition of most sediment coarser than fine sand within these channels or on the road surface (Bilby et al. 1989; Megahan \& Ketcheson, 1996). Through the experimental addition of sediment to drainage channels, Duncan et al. (1987) found that between 90 and $95 \%$ of sand $(0.5-2.0 \mathrm{~mm})$ was retained in these channels, while almost all sediment $<0.063 \mathrm{~mm}$ travelled through the system; the rate of sediment retention is strongly related to grain size. In certain circumstances, coarser sediment can also enter stream channels: if no buffer between road and channel exists and road fill-slopes are unprotected by erosion-resistant material (e.g. riprap), coarser sand and gravel may enter channels directly as a result of road surface runoff: Lane and Sheridan (2002) noted that 2-3 tons of bedload material had entered a stream adjacent to a fill-slope impacted by rill erosion from road runoff. Efforts are generally made to protect road fill-slopes and embankments from lateral stream erosion (Province of B.C., 2002) limiting road-derived bedload material input, therefore contributions of sediment to streams from forest road surfaces consist primarily of suspended material.

\subsection{In-stream effects of road surface sediment}

Although the controls on sediment production from forest road surfaces are fairly well understood, the effect of the introduction of this sediment to streams has been relatively little studied. Works 
reporting the in-stream effects of road surface sediment are summarized in Table 1. In a western Washington stream, suspended sediment concentrations (SSC) were found to be up to $275 \%$ higher below than above a stream crossing during moderate rainfall events, and instances of high concentrations more frequent (Bilby, 1985; Bilby et al. 1989). Additionally, Lane and Sheridan (2002) found that total SS yield increased by a factor of 3.5 downstream of a stream crossing. More severe impacts were reported by Thomaz et al. (2013), who found that at 4 of 6 monitored stream crossings, downstream SSC was between 3.5 and 10 times higher than upstream.

Even though roads can increase SSC input, road related sedimentation in the stream channel bed appears to be minimal over the long term. For example, Bilby et al. (1989) could not discern any difference in the grain size distribution (GSD) of bed material above versus below a 30 year old stream crossing, even though this same crossing significantly elevated SSC downstream. Current research has suggested that downstream deposition may be significant only during periods of low streamflow and reduced water velocities (Bilby 1985; Bilby and Ward, 1985; Lane \& Sheridan 2002); as river fauna and water quality are most sensitive during these periods, even temporary sedimentation may prove detrimental. Uncertainty of impacts remain as a result of limited empirical evidence.

The contributions to stream sediment yields from road surfaces are variable and dependent on the landscape in which the roads are situated. In a paired-basins study in the Oregon Coast range, Beschta (1978) did not detect fine sediment input from road surfaces because input to streams was dominated by road-initiated mass movement events. However, a partial basin-wide sediment budget by Reid (1981) revealed that $19 \%$ of all road-related material was from surface erosion, but this value was not placed in the context of other sediment sources in the basin. Using 
Table 1: Summary of studies examining in-stream effects of road surface sediment.

\begin{tabular}{|c|c|c|c|c|}
\hline Reference & Catchment & Study location & Methods & Main findings \\
\hline $\begin{array}{l}\text { Bilby, 1985; Bilby et } \\
\text { al., } 1989\end{array}$ & Johnson Creek & $\begin{array}{l}\text { Washington, } \\
\text { USA }\end{array}$ & $\begin{array}{l}\text { Pump sampler collects water } \\
\text { samples at crossing. Field } \\
\text { observations of stream channel. }\end{array}$ & $\begin{array}{l}\text { Turbidities }>30 \text { NTU occur } 6.5 \mathrm{X} \text { more often downstream } \\
\text { than upstream of a road crossing. Peak NTU downstream } \\
2.75 \mathrm{X} \text { higher than upstream. } 21 \% \text { of annual sediment load } \\
\text { contributed from stream crossing. Road surface sediment } \\
\text { not deposited in stream channel in significant quantities. }\end{array}$ \\
\hline Duncan et al., 1987 & Mack Creek & $\begin{array}{l}\text { Washington, } \\
\text { USA }\end{array}$ & $\begin{array}{l}\text { Experimental addition of sediment } \\
\text { to ditch drainage channels }\end{array}$ & $\begin{array}{l}\sim 95 \% \text { of sediment }>0.5 \mathrm{~mm} \text { retained in drainage channels, } \\
\text { while nearly all sediment }<.063 \mathrm{~mm} \text { passes through } \\
\text { channels. }\end{array}$ \\
\hline $\begin{array}{l}\text { Sheridan and Noske, } \\
2002\end{array}$ & Stony Creek & $\begin{array}{l}\text { Victoria, } \\
\text { Australia }\end{array}$ & $\begin{array}{l}\text { Turbidity monitoring up and } \\
\text { downstream of stream crossing. } \\
\text { Simulated rainfall to generate road } \\
\text { runoff. }\end{array}$ & $\begin{array}{l}\text { SS yield increases by factor of } 3.5 \text { downstream of road } \\
\text { stream crossing. Road fill slope erosion deposits bedload } \\
\text { sediment in channel. }\end{array}$ \\
\hline Thomaz et al., 2013 & $\begin{array}{l}\text { Guabiroba } \\
\text { River }\end{array}$ & Southern Brazil & $\begin{array}{l}\text { SSC monitoring at six unpaved road } \\
\text { stream crossings }\end{array}$ & $\begin{array}{l}\text { SSC downstream of stream crossings between } 3.5 \text { and } 10 X \\
\text { higher than upstream }\end{array}$ \\
\hline Reid et al., 1981 & $\begin{array}{l}\text { Clearwater } \\
\text { River }\end{array}$ & $\begin{array}{l}\text { Washington, } \\
\text { USA }\end{array}$ & $\begin{array}{l}\text { Stream gauging, formulation of } \\
\text { partial sediment budget. }\end{array}$ & $\begin{array}{l}20 \% \text { of total road related sediment production is from } \\
\text { surfaces }\end{array}$ \\
\hline $\begin{array}{l}\text { Gruszowski et al., } \\
2003\end{array}$ & River Severn & $\begin{array}{l}\text { Herefordshire, } \\
\text { U.K. }\end{array}$ & $\begin{array}{l}\text { Non-linear mixing model to } \\
\text { fingerprint sediment sources }\end{array}$ & $\begin{array}{l}30 \% \text { of total sediment yield either passed emanated from } \\
\text { unpaved forest roads. }\end{array}$ \\
\hline Motha et al., 2003 & $\begin{array}{l}\text { West Tarago } \\
\text { River }\end{array}$ & $\begin{array}{l}\text { Victoria, } \\
\text { Australia }\end{array}$ & $\begin{array}{l}\text { Mixing model used to fingerprint } \\
\text { sediment sources. }\end{array}$ & $\begin{array}{l}12 \text { and } 25 \% \text { of the total sediment yield came from, } \\
\text { respectively, graveled and un-graveled road surfaces. }\end{array}$ \\
\hline Baird, 2011 & Honna River & $\begin{array}{l}\text { British } \\
\text { Columbia, } \\
\text { Canada. }\end{array}$ & $\begin{array}{l}\text { Assessment of drainage channel } \\
\text { sediment delivery and connectivity } \\
\text { to main river channel }\end{array}$ & $\begin{array}{l}\text { Between } 5 \text { and } 35 \% \text { of total sediment yield sourced from } \\
\text { unpaved road surfaces. }\end{array}$ \\
\hline
\end{tabular}


a non-linear mixing model, Gruszowski et al. (2003) found that in a predominantly agricultural, low relief watershed, $30 \%$ of the SS load was either generated from, or transported via unpaved forest roads over a two year period. Similar results were reported by Motha et al. (2003) who found that 18 to $39 \%$ of the in-stream SS load was from unpaved forest road surfaces. More recently, a study by Baird (2011) of sediment leaving an unpaved road surface led to estimates that between 5 and $35 \%$ of the suspended material yield for a one year period was sourced from this road surface.

\subsection{Study objectives}

Sediment balances are useful tools to examine sources, sinks, and changes in storage in rivers. In particular, balances are effective frameworks to examine anthropogenic impacts to stream systems (e.g Beschta, 1978; Roberts and Church, 1986; Hudson, 2001; Jordan, 2006). In the Pacific Northwest, resource road surface sediment may constitute an important component of suspended sediment balances, yet few studies (eg. Reid et al., 1981; Gruszowski et al., 2003; Motha, et al., 2003) have addressed the balance component accounted for by road surface sediment input, and none have directly measured this input or examined it at the reach scale.

Although previous studies have provided valuable insight into the contributions of road surface sediment at the basin and stream crossing scale, empirical evidence remains limited, and in-stream effects at reach scale (> 30 channel widths) cannot be assessed with these approaches. Additionally, reported basin-scale assessments rely on the assumption that all sediment leaving road surfaces enters streams, which is known to be false if a buffer between road and channel exists (Duncan et al., 1987). Although reach balance results may not easily be applied at the watershed scale, they are nonetheless advantageous since more complete input, storage, and output terms can be assembled, and local changes in balance components can be examined in greater detail (Smith 
et al., 2003; Hassan et al. 2010; Hassan et al., 2011). Additionally, little work has been done whereby balance components have been measured directly; often, road surface inputs are inferred or modelled, resulting in high uncertainty of estimates. Given the apparent significance of resource road surfaces as a source of sediment to streams, a greater understanding of the contributions of road surface sediment relative to other, natural sediment sources at the reach scale is needed.

During 2009, a study was conducted in the Honna River watershed to examine the primary controls on the production of sediment from an unpaved road surface (van Meerveld et al, 2014) whereby rainfall intensity and traffic were found to most strongly control sediment production. As a follow up to the van Meerveld et al. (2014) study, this paper aims to fill the aforementioned gaps in knowledge by examining the effects of road surface material at the reach scale in the same location as research undertaken by van Meerveld et al. (2014). Therefore, the primary goal of this study is to construct a reach-scale sediment balance to assess the relative effects of road surface sediment on in-stream sediment dynamics and yield. Specific objectives of this study are:

1. Determine event-based and seasonal variation in SSC and its relation to water discharge and characterize temporal patterns of sediment concentrations from road surfaces and within the study reach;

2. Develop a reach-scale sediment balance to determine the different source contributions, with a specific focus on contributions from the road surface;

3. Describe spatial and temporal dynamics of road surface sediment contributions to the study reach sediment load at the event and month scale. 


\section{Chapter 2: Study area}

\subsection{The Honna River watershed}

The Honna River watershed is located off of the north coast of British Columbia, on Graham Island, part of the Haida Gwaii archipelago. The river drains into Skidegate Inlet $4 \mathrm{~km}$ northwest of the Village of Queen Charlotte (pop. 900) and is the town's primary source of drinking water (Figure 1). The basin is located in the Coastal Western Hemlock biogeoclimatic zone CWHvm (Meidinger \& Pojar 1991), and experiences a rain-dominated flood regime with some snow at higher elevations. Although rainfall data has been collected at three locations in the watershed since 2009, no long-term climate monitoring stations exist in close proximity to the basin, the nearest is located in the town of Sandspit (Figure 1). Annual average precipitation in Sandspit totals $1154 \mathrm{~mm}$, the majority falling as rain in the fall and winter months (Environment Canada, 2014). Baird (2011) compared rainfall totals at three locations within the Honna basin to those at Sandspit over a one year period, and found that totals ranged from 2210 to $1980 \mathrm{~mm}$, much higher than the $999 \mathrm{~mm}$ recorded in Sandspit for that period. This difference in precipitation is likely a result of the greater orographic effect observed in the mountainous Honna basin than in the relatively flat terrain surrounding Sandpit.

The river at the mouth is a $5^{\text {th }}$ order channel, draining a $52 \mathrm{~km}^{2}$ watershed with the mainstem generally of riffle-pool morphology, although some localized bedrock exposures are present: additional characteristics of the main channel are summarized in Table 2. Numerous large wood accumulations are found along the channel, many of which have led to major channel avulsions. Basin topography is varied, with elevations ranging from sea level to just over $1000 \mathrm{~m}$. The watershed has a siltstone and mudstone dominated lithology, overlain by a 2-3 m thick layer 


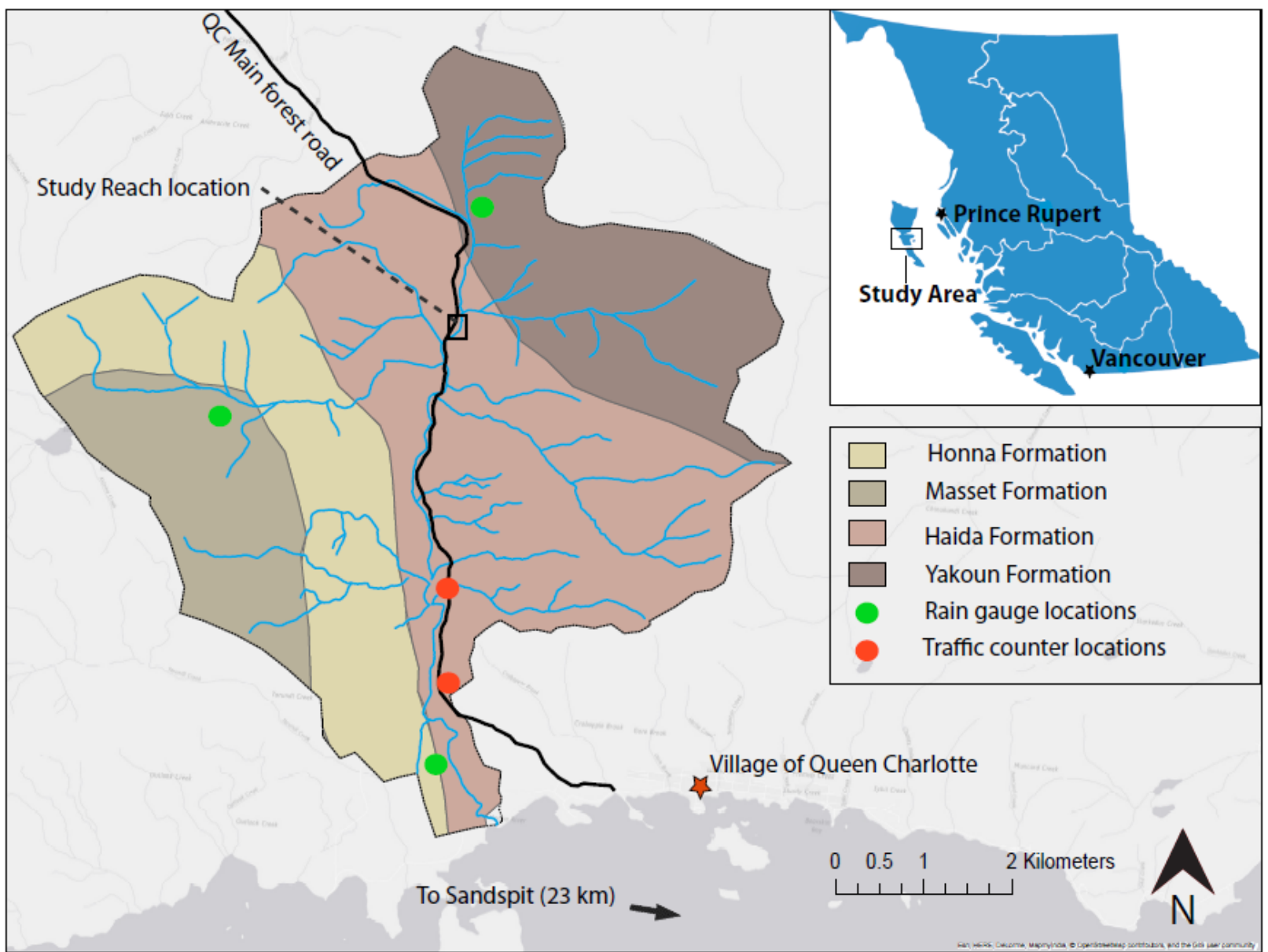

Figure 1: Honna River basin and geology with location of study reach and QC Main forest road noted. Rain Gauges and traffic monitoring sites were installed prior to this study. Details of geology can be found in Haggart, 2004.

of colluvial material deposited during the most recent glaciation (Haggart 2004). Steep slopes and relatively thick alluvial sediment cover has led to several slope failures in two of seven of the largest sub-basins, consistent with the high spatial frequency of slope failures observed throughout mountainous areas of Haida Gwaii (Rood 1984; Schwab 1998).

The Honna River basin has experienced widespread intensive timber harvesting since the mid-1970's, including riparian zone logging, as determined from the British Columbia Vegetation 
Resource Inventory (http://www.for.gov.bc.ca/hts/vri/). To enable access to timber, an extensive network of logging roads was constructed in the basin over the past 50 years, with total road distance exceeding $90 \mathrm{~km}$ (Dobson Engineering Ltd. 1996). After harvesting, secondary roads have been deactivated following B.C. Provincial Ministry of Forests protocol (Province of British Columbia 2002), therefore many of the $90 \mathrm{~km}$ of resource roads are no longer in use, have partly re-vegetated, and are not considered to be major sediment sources in the basin.

Some roads remain actively used, however, and of particular interest is the Queen Charlotte Main, (hereafter referred to as the QC Main), a 10 meter wide mainline logging road which runs parallel to the main stem of the Honna River, frequently within 20 meters of the channel. The QC Main follows the Honna main channel for approximately six kilometers before branching off to the east near the northern limit of the Honna River basin (Figure 1). The road has an average grade of $3 \%$, and is surfaced with soft sedimentary rock quarried from the surrounding landscape (Dobson Engineering Ltd., 1996), most recently resurfaced in 2008. The road experiences heavy industrial and recreational traffic, especially during summer months. Although the QC Main passes through moderate terrain and has small or no cut-slopes, its close proximity to the Honna River and soft surfacing material leads to a high potential for hydrologic and sedimentary connectivity between the road and river mainstem.

\subsection{Honna River study reach}

To examine the sediment dynamics in the Honna River, a reach of the mainstem was selected for measurement and instrumentation in August 2012. The $425 \mathrm{~m}$ reach is located approximately 7.5 $\mathrm{km}$ upstream of the channel mouth (Figure 1), and is mostly of riffle-pool morphology. Reach morphology is strongly controlled by large wood in the river channel; four channel-spanning jams 


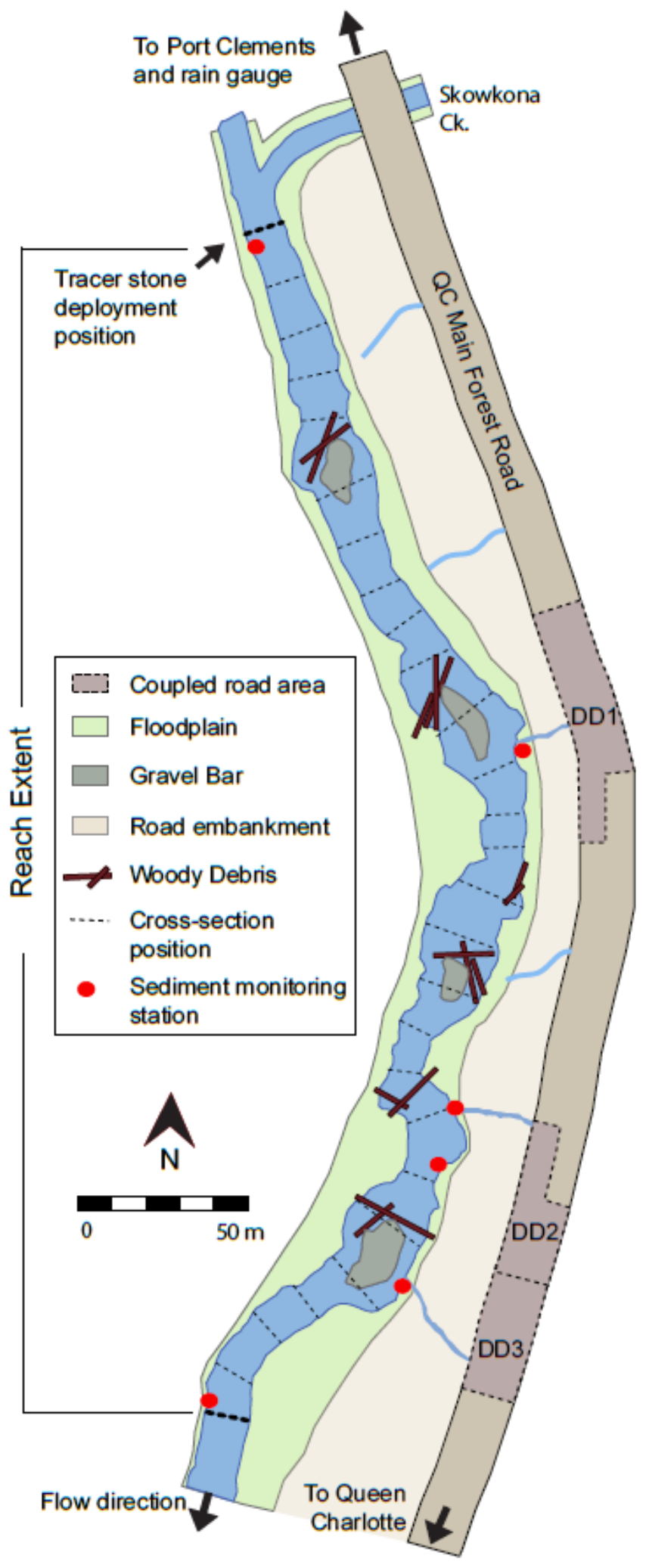

Figure 2: Honna River study reach and QC Main forest road with road contributing area highlighted. and two large wood accumulations are found adjacent to the largest pools in the reach, and gravel bars stabilized with vegetation are found downstream of the two largest jams. The reach is bounded by the entrance of Skowkona Creek to the north and Honna Northwest Creek to the south (Figure 2). Channel gradient is relatively low for a mountainous area (Table 2), and the reach is predominantly single-thread, although large wood obstructions divide the channel in three locations, and two small backchannels, flooded only at relatively high water, are found along the left bank. Channel width varies from $8 \mathrm{~m}$ to $20 \mathrm{~m}$ near the largest $\log$ jams. The QC Main runs parallel to the reach at a distance of 10 to 30 meters, separated by a gradually sloping road embankment and a narrow floodplain (Figure 2). Core samples of the oldest riparian trees reveal that floodplain age is less than 150 years, and floodplain soil depth ranges from 10 to $20 \mathrm{~cm}$. The right bank of the channel runs at the base of a gradual slope. 
Six ditch drainage exit points are located along the segment of the QC Main road running parallel to the study reach. Three of these drainages are connected directly to the main river channel, while the remaining drainages empty onto the buffered area between the channel and the road. Sediment from the road surface has been observed entering the reach from the three channelized drainages and from subsurface flow in locations where the distances between the channel and road embankment are small. All three channelized drainages have a persistent baseflow in fall and winter months, originating from subsurface water intercepted by the upslope road cut, but this flow does not appear to contribute any additional sediment to the drainage channels. Summaries of study reach and drainage channel characteristics are found in Table 2. In order to reduce the ditch water velocities and, in turn, the quantity of sediment entering coupled drainage channels, vegetated ditch blocks had been installed several years prior to the study along much of the QC main.

Table 2: Honna River basin and study reach physical characteristics.

\begin{tabular}{llllllll} 
& $\begin{array}{l}\text { Length } \\
\text { Channel of interest }\end{array}$ & $\begin{array}{l}\text { Wh } \\
(\mathrm{m})\end{array}$ & $\begin{array}{l}\text { Gradient } \\
(\mathrm{m} / \mathrm{m})\end{array}$ & $\begin{array}{l}\text { Contributing } \\
\text { catchment } \\
\text { Area }\left(\mathrm{km}^{\wedge} 2\right)\end{array}$ & $\begin{array}{l}\text { Contributing } \\
\text { Road Area }\end{array}$ & $\begin{array}{l}\mathrm{D}_{50^{+}} \\
(\mathrm{mm})\end{array}$ & $\begin{array}{l}\text { Dominant } \\
\text { Morphology }\end{array}$ \\
\hline Honna River Main Stem & 9354 & $17^{*}$ & 1.7 & 52.1 & 60 & - & $\mathrm{R} / \mathrm{P}^{\$}$, Bedrock \\
Study Reach & 428 & 12.1 & 0.9 & $12.5^{* *}$ & 4.3 & 38 & $\mathrm{R} / \mathrm{P}$ \\
DD1 & 31 & 1.25 & 3 & $4.7^{*} 10^{\wedge}-5$ & 0.47 & 11 & - \\
DD2 & 22 & 0.95 & 4.1 & $2.0^{*} 10^{\wedge}-5$ & 0.2 & 45 & - \\
DD3 & 28 & 0.75 & 4.9 & $1.9 * 10^{\wedge}-5$ & 0.19 & 45 & - \\
\hline
\end{tabular}

*At Environment Canada Gauging Station, $1 \mathrm{~km}$ from river mouth

** Upstream of lower reach limit

$\$$ Riffle-pool

$\$$ Bankfull Width

${ }^{+}$Median grain size 


\section{Chapter 3: Methods}

\subsection{Field data collection methods}

\subsubsection{Collection of turbidity and discharge data}

To examine SS dynamics and to characterize the fine sediment component of the study reach balance, hydrologic and SS monitoring stations were installed at 6 locations (Figure 2). All sites were monitored over a 16 month period from September $1^{\text {st }}, 2012$ to December $31^{\text {st }}, 2013$, although for the balance, only 12 months of data (September 2012-end of August 2013) were used. Stations were located at the upstream and downstream limits of the reach, and on the three coupled ditch drainage channels close to their intersection with the river. A $6^{\text {th }}$ station was installed mid-way down the reach to help characterize downstream changes in sediment dynamics.

At each station, turbidity data were collected using Analite NEP 9000 turbidity probes (McVan Instruments Pty Ltd.) with a range to 400 NTU in the main channel and 1000 NTU in ditch drainage channels, coupled to data loggers reading at 30 second intervals. Every 15 minutes, the average, maximum and minimum turbidity values from all scans within the previous 15 minute period were stored Starlogger data loggers (Unidata Pty. Ltd.). Water level data were collected using capacitance water level recorders (Odyssey Data Recording), logging at 15 minute intervals, and velocity-area discharge measurements were taken at each site to develop stage-discharge rating curves.

Water samples containing suspended material were collected in the main channel and ditch drainage channels to develop SSC-turbidity rating curves for calculation of suspended material load. Previous studies (eg. Gippel, 1995; Wilde and Gibs, 1998; Lewis \& Eads, 2001) have shown 
that differences in particle shapes, colours, and sizes can lead to varied turbidity readings between rising and falling hydrograph limbs, and also seasonally for a given location. Throughout the study period, $500 \mathrm{ml}$ grab samples were collected under a variety of flow conditions to develop representative SSC rating curves. However, given limited on-site field time and accessibility, insufficient samples were collected (15 in ditch drainage channels and 22 in the main river channel) to generate separate relations for different seasons or flow conditions, and were separated only into road and in-channel SS. Samples were processed following USGS guidelines (see Uhrich \& Bragg 2003), using vacuum filtration through wet sieves at half-phi intervals.

\subsubsection{Sediment input from bank retreat}

The contribution of bank material to the reach was assessed through the measurement of 27 topographic cross-sections at roughly 15 meter intervals downstream, and rebar bank erosion pins were installed in 10 additional locations of noted erosion (Figure 2), following Lawler (1993). Cross-sectional measurements were undertaken with a tape and level, and length of bank erosion pins measured with a rigid ruler. To estimate total volume of channel bank eroded, bank dimensions were measured at each cross section, and $92 \%$ of the total channel bank length was determined to be composed of erodible material. Bulk samples of bank material collected at two locations in the reach revealed that about $84 \%$ of material by mass is of bedload texture, and the remaining $16 \%$ is composed of fine sediment $<0.35 \mathrm{~mm}$ able to move in suspension.

\subsubsection{Bedload sediment flux}

Bedload material flux was estimated through the use of painted and magnetically tagged tracer particles (see Hassan and Ergenzinger, 2003; Hassan et al., 2014). Tracer stones were 
manufactured and deployed following methods outlined in Hassan \& Ergenzinger (2003), and Eaton et al. (2008). The distribution of size classes for tracer stones was based on the median grain size of the bed surface sediment in the study reach (Table 2), determined through Wolman particle counts. 90 stones between 22.5 and $32 \mathrm{~mm}, 65$ between 32 and $45 \mathrm{~mm}$, and 65 between 45 and 64 $\mathrm{mm}$, all painted and labelled according to their size class, were deployed in lines at the upper end of the reach in August 2012. Additionally, 120 stones, 40 in each size class, were painted without magnets and inserted in the same location.

Stones were recovered one year after deployment using a magnetic locator or visual location for non-magnetic stones. As tracer stones were recovered only once, transport data incorporates movement over the year, and not at the event-scale. Travel distances were measured in relation to a survey tape placed along the reach thalweg, and burial depth for each stone was recorded upon recovery. The recovery rate for magnetic and painted stones were $88 \%$ and $81 \%$, respectively, and fairly even among size fractions (Table 2). Using a downstream measurement error of $0.5 \mathrm{~m}, 69 \%$ of recovered stones were found to have been transported from the deployment position.

\subsubsection{Measured change in suspended and bedload sediment storage}

Change in storage of fine sediment settled on the channel bed was estimated from samples of settled sediment collected following Lambert and Walling, (1988), Walling et al. (2006), and López-Tarazón et al., (2012). A PVC (polyvinal chloride) cylinder (0.5 m long; inner diameter of $0.35 \mathrm{~m}$ ) was used to isolate segments of the channel bed. The coarse texture of the channel bed surface material led to difficulties in forming a seal between bed and cylinder, therefore a flexible rubber baffle was attached over the end of the cylinder in contact with the bed to prevent fine 
material from getting washed out of the cylinder. When the channel bed was isolated, the surface layer of sediment (to a depth of the median grain size for that sample location) was agitated vigorously, and a $500 \mathrm{ml}$ sample of water from the cylinder was collected. At least two samples were collected at 27 equally-spaced positions along the study reach, one near the thalweg, and another close to the bank to capture storage variability, following Walling et al. (2006).

In the summer of 2013, between three and ten water samples were collected at each cross section to describe variation in sediment availability on the channel bed. The sample average at each cross-section was taken to provide a single value of fine sediment storage for that location. Wetted channel width was measured at each channel cross section, and the water depth in the cylinder was measured upon sampling for later calculation of bed surface sediment availability. Samples were collected in August 2012, December 2012, February and March 2013, and July 2013. Samples collected at the three instances in winter were combined into a single group, as sample numbers were limited, and t-tests for winter sub-group means concluded no significant difference between them.

As bedload sediment transport is measured only within the reach, change in storage must be measured directly. Change in channel storage of bedload material as examined through the comparison of bed elevations determined from repeat topographic cross-sectional measurements, following Lawler (1993).

\subsubsection{Additional field measurements}

Dimensions and surface sediment characteristics of the three coupled drainage channels were measured (Table 2). Total road area adjacent to the reach was determined, and the contributing area to individual drainage channels was surveyed with a hand tape and level. Rainfall and traffic 
data were also collected within two km of the study reach over a 16 month period. Traffic counters (TRAFx Research Ltd.) were able to distinguish between industrial and non-industrial traffic, and yielded data in both hourly-total and timestamp form.

\subsection{Reach scale sediment balance formulation}

Although 16 months of suspended-sediment data were collected, for this study, input from bank erosion and directly measured change in channel bed storage were assessed over a 12 month period, therefore the suspended material balance is also limited to this annual range. The formulation of the reach-scale sediment balance follows Smith et al. (2003a, 2003b), and Hassan et al. (2010 and 2011). As with other studies, the reach sediment balance can be written as

$\Delta S=I-O$

Where $\Delta S$ is the storage term, $O$ is the outputs and $I$ is the inputs into the reach. The inputs to the reach for suspended material are described in Eq. 2:

$I_{s s}=I_{r}+I_{u s}+I_{b e}+I_{h s}$

and for bedload, Eq 3:

$I_{b}=I_{u s}+I_{b e}+I_{h s}$ 
Where $I_{r}$ is sediment input from the road surface, $I_{u s}$ is input from upstream, $I_{b e}$ is input from bank erosion, and $I_{h s}$ is input from hillslope mass movement. Output terms for suspended material (Eq. 4) in the balance are presented as:

$$
O_{s s}=O_{f p}+O_{d s}
$$

Where $O_{f p}$ is material lost to the floodplain, and $O_{d s}$ material leaving the reach downstream. For bedload, overbank deposition of material is assumed negligible, therefore output can be presented as $(\operatorname{Eq} 5)$ :

$O_{b}=O_{d s}$

For the reach of interest in this study, $I_{u s}$ is considered to be all sediment passing the upper end of the reach, $I_{r}$ the sum of sediment passing through the three coupled ditch drainage channels, and $I_{b e}$ all sediment entering the channel from erosion of both banks. Slopes adjacent to the reach are heavily forested and show no evidence of rilling, failure, or surface water contribution, therefore $I_{h s}$ is considered negligible. In terms of output, $O_{d s}$ consists of sediment passing the lower reach limit. $O_{f p}$ is considered negligible over the period of study as (1) total floodplain area is minimal, and (2) overbank flooding was not observed. As suggested by Hassan et al. (2010 and 2011), the floodplain can be considered part of the channel, and can thus be included within the $\Delta S$ term. 


\subsection{Determination of reach sediment balance components}

\subsubsection{Suspended sediment upstream inputs, road surface inputs, and reach outputs}

To obtain suspended-sediment yields from turbidity and discharge data, SSC-turbidity rating curves were developed from collected water samples. After initial inspection of turbidity data, a decision was made to use the minimum turbidity values reported in the 15 minute logging window, as this data presents a conservative minimum, and was also of higher quality than the average or maximum turbidity data. Turbidity data in the study reach occasionally suffered from excess noise due to aeration of the water column or debris fouling. Some periods of unusable data were present at all but one of the sediment monitoring stations, and in these cases, relations with nearby monitoring stations with reliable data were used to fill gaps. Aside from the DD1 (Figure 2) monitoring station, where a turbidity probe was deployed only briefly, these periods of missing data were generally short (Table 3$)$, and relations with other sites were strong $\left(\mathrm{R}^{2}>0.9\right)$. The lack of a suitable turbidity probe mounting location at the DD1 site limited deployment time to a single week in June, 2013, although stage was monitored continuously from January 2013 onward: this is reflected in the greater sediment yield prediction error at this site.

Given the homogeneity of source sediment leaving the road surface, and that only the finest material generally travels from road surfaces to streams (Duncan et al., 1987; Bilby et al., 1989; Megahan and Ketcheson, 1996), it was assumed that the physical properties of river and ditch drainage SS would differ and require separate relations. SSC-turbidity rating curves for both inchannel and ditch drainages are presented in Figure 3. These findings suggest that separating rating curves between road surface sediment and sediment found within the river is justified. 
Table 3: Suspended-sediment yield error components and terms.

\begin{tabular}{|c|c|c|c|c|c|c|c|}
\hline & \multirow{2}{*}{$\begin{array}{l}\text { Stage } \\
\text { Missing data period }\end{array}$} & \multicolumn{4}{|c|}{ Turbidity } & \multirow[b]{2}{*}{$\begin{array}{l}\text { SSC-turbidity } \\
\text { Rating curve } \\
\text { error (\%) }\end{array}$} & \multirow[b]{2}{*}{$\begin{array}{l}\text { Load estimate } \\
\text { Total error* } \\
(\%)\end{array}$} \\
\hline & & $\begin{array}{c}\text { Relation** } \\
\text { error }(\%)\end{array}$ & Missing data period & $\begin{array}{l}\text { Relation } \\
\text { error (\%) }\end{array}$ & $\begin{array}{l}\text { Discharge } \\
\text { error (\%) }\end{array}$ & & \\
\hline Reach inlet & Sept-Dec 2012, Nov-Dec 2013 & 1.2 & Sept-Nov 2012 & 14 & 13 & 29 & 35 \\
\hline Reach outlet & Nov-12 & 0.2 & - & 0 & 14 & 29 & 32 \\
\hline DD1 & Sept-Dec 2012 & 1 & Sept 2012 - Feb 2013 & 25 & 33 & 24 & 47 \\
\hline DD2 & $-* *$ & - & - & 0 & 6 & 24 & 25 \\
\hline DD3 & - & - & - & 0 & 1 & 24 & 24 \\
\hline
\end{tabular}

* includes all error terms. Error is less when no data gaps exist.

**"Relation error" indicates error arising from the filling of data gaps. 


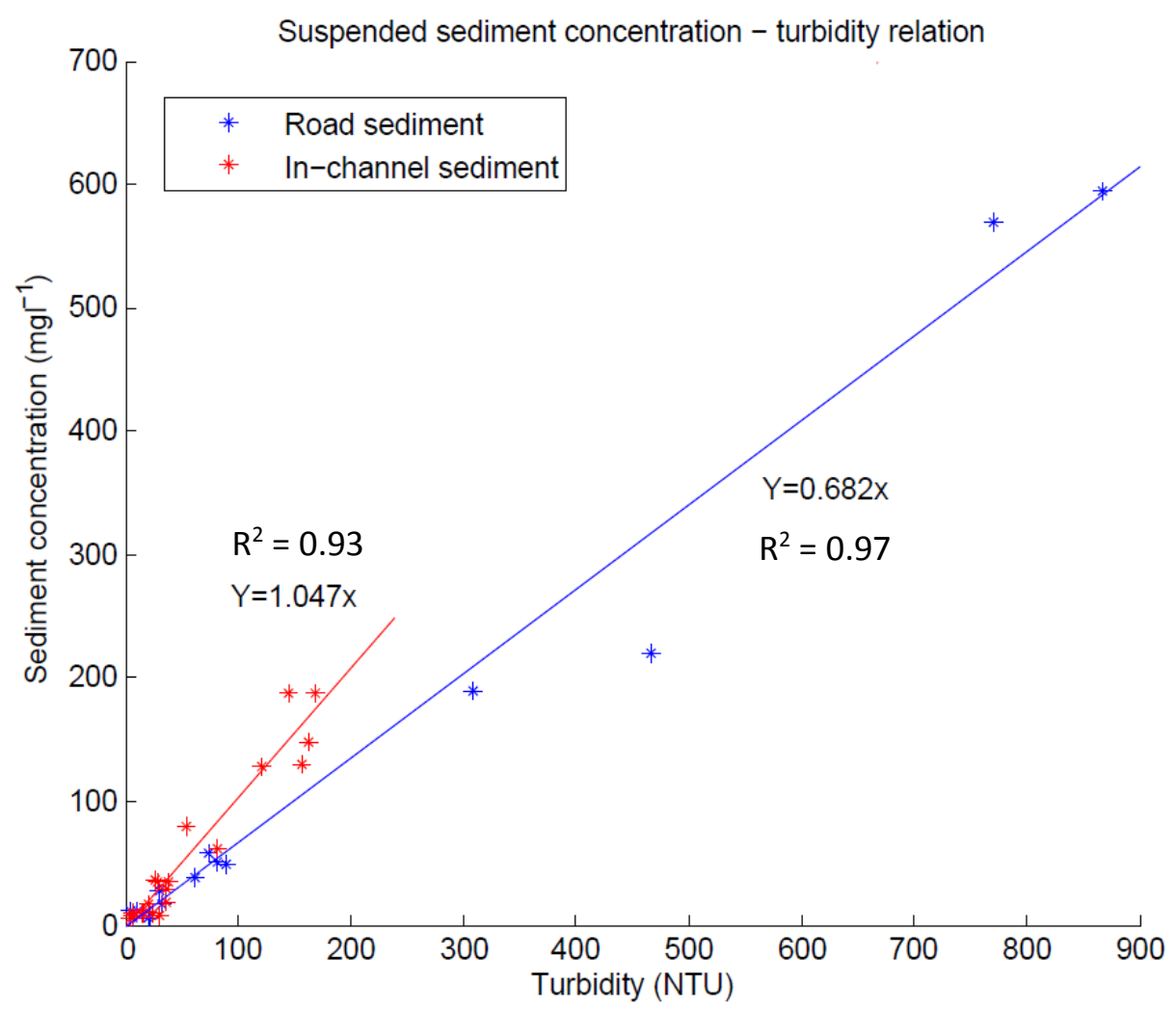

Figure 3: SSC-turbidity relations for suspended material in-channel and from road surface in the Honna River basin.

Although there is some scatter in both relations, linear fitting represents the data well. Scatter in the relations represents within-event and seasonal variability in sediment characteristics. The slopes of the curves for sediment in-channel and leaving the road surface are significantly different at $p=.05$, with the relation for SSC in the river reach having a slope of 1.05 , almost unity, and that of sediment from the road surface a slope of 0.68 . Substantial scatter in the relation for in-channel SSC was observed for samples with low turbidities; since the maximum turbidity of any sample collected within the study reach main channel was below 200 NTU, obtaining samples with higher readings could help improve this relation. 
Once turbidity and discharge time series data had been inspected for noise and sections of low-quality data, and the SSC-turbidity rating curves applied, suspended-sediment flux time series could be calculated for sediment leaving the road surface and passing through the study reach. As both turbidity and discharge are measured simultaneously and in a quasi-continuous fashion, total sediment load $\left(M_{S}\right)$ passing a given monitoring station can be calculated following Smith et al. (2003) as:

$$
M_{S}=\Delta t \int_{t=0}^{t=T} Q_{t} S S_{t}
$$

Where $Q_{t}$ is the water discharge, $S S_{t}$ is suspended sediment concentration, $\Delta t$ the period between sampling intervals, $t$ the time interval, and $T$ the number of time intervals over which the sediment mass has been calculated.

\subsubsection{Suspended sediment flux uncertainties}

Uncertainties in the calculation of SS load result from errors in determining SSC and water discharge from turbidity and stage data. Error sources in estimating the discharge include errors in individual discharge and water level measurements, generalization of stream cross sections, instrument error, and operator error (Sauer \& Moyer 1992). Errors in accurately capturing a stream's cross-sectional profile may be of particular importance in relatively small gravel bed streams, where individual clasts or wood accumulations can dominate channel morphology. For this study, uncertainty in discharge measurements were calculated following methods in Taylor (1997), where errors in the stage-discharge rating relation at each site are added in quadrature to 
any error arising from the filling of gaps in stage data record. Relative error for discharge $\left(E_{q}\right)$ can therefore be expressed as:

$E_{q}=\sqrt{\left(E_{q r c}\right)^{2}+\left(E_{q g a p}\right)^{2}}$

where $E_{q r c}$ is the relative error from stage-discharge rating curves, and $E_{\text {qgap }}$ the relative error of any relations between sites with missing data and nearby sites.

Errors in discharge ranged between $5 \%$ at the reach outlet to $32 \%$ at ditch drainage \#3 (DD3), with an average of $13 \%$ across sites. Discharge measurements at DD2 and DD3 were taken at a culvert outlet, and the higher uncertainty at DD3 is likely a result of water entering the drainage channel below the outlet, affecting the water level reading. These errors are slightly higher than but similar to the values of 5-10\% reported in other reach-scale SS balances (Hassan et al., 2010, 2011; Mclean et al., 1999; Smith et al., 2003b), although channels in these studies are all much larger and not necessarily comparable to the Honna River study reach.

As distinct rating curves were developed to determine SSC in the river and in ditch drainage channels, uncertainty estimates were determined for each curve separately. For a given SSC measurement, error is composed of the standard error of the SSC-turbidity rating curve, and any rating curves between a site with missing data and a nearby site. Additional uncertainty arises in laboratory processing, but these are considered systematic and are therefore not included. Error in the determination of SSC from turbidity can therefore be expressed as:

$$
E_{s s c}=\sqrt{\left(E_{s s c r c}\right)^{2}+\left(E_{\text {sscgap }}\right)^{2}}
$$


Where $E_{S s c}$ is total relative error in SSC prediction, $E_{s S c r c}$ the relative error from SSC-turbidity rating curve, and $E_{\text {sscgap }}$ the relative error of any relations between sites with missing data and a nearby site. Errors for the in-channel and ditch-drainage SSC-turbidity rating curves were 29 and $24 \%$, respectively.

Finally, the total error in sediment yield for a given time period can be calculated by combining the previous two terms in quadrature, as:

$$
E_{y}=\sqrt{\left(E_{q}\right)^{2}+\left(E_{s s c}\right)^{2}}
$$

where $E_{y}$ is the total relative error in sediment yield. Table 3 compares total error for each site, as well as the component errors. As the SSC-turbidity rating curve dominates the total error term and is fairly similar between ditch drainage and the main river channel, the total relative error terms for sediment yield are fairly similar across all sites, roughly in the order of $+/-30 \%$. This is somewhat higher than values reported in Smith et al. (2003a, b), where sediment load uncertainty was in the order of $10-20 \%$. Hassan et al. $(2010 ; 2011)$ estimated annual sediment load uncertainties in the Changjiang (Yangtze) River to be in the order of 10\%, but their channel of interest is substantially larger. Webb et al. (1997) found errors associated with the estimation of sediment load from rating relationships in eastern England to be somewhat higher, in the order of 29-57\%. Errors reported in Hassan et al. (2010 and 2011) and Smith et al. (2003) are lower than those reported in this study for two possible reasons. Channels in all three studies had fairly longterm flow and sediment monitoring, with many more samples used to create rating curves than for 
this study. Additionally, Smith et al. (2003b) separated SSC-turbidity rating curves by individual storm event, thereby further reducing variability. Although the errors reported in this study are somewhat higher than others, these results are the best possible given the available data and field time, and to not significantly detract from the validity of the analysis.

\subsubsection{Estimation of sediment input from bank erosion}

Estimates of the sediment input yield $\left(I_{b e}\right)$ to the reach from bank erosion can be expressed as

$I_{b e}=\left(L_{b} H_{b} R p\right) 1.6$

Where $L_{b}$ is the length of erodible bank material (m), $H_{b}$ the average height of erodible banks (m),

$R$ the average bank retreat rate $(\mathrm{m}), p$ the proportion of eroded material that is either suspended or bedload sediment, and 1.6 the density of bulk sediment in $\mathrm{gcm}^{-2}$. Error in bank material input as estimated from cross-sectional measurements and retreat pins was calculated as the standard error of the average of retreat rates and channel dimensions at individual measurement locations. Individual measurement error is assumed to be low relative to the variability between cross sections. Several studies (reported in Lawler, 1993) note that banks may swell or contract normally as a result of slumping or changes in water content, which might also lead to $0.3-1.5 \mathrm{~cm}$ of uncertainty in measurements. As banks in the study reach are composed primarily of coarse material, this effect was considered negligible. 


\subsubsection{Bedload sediment flux estimate}

As bedload transport is determined within the reach, values are assumed to represent both $I_{u s}$ and $O_{d s}$. From the magnetic tracer stone field data, an estimate of bedload flux $\left(Q_{b}\right)$ can be calculated following Church \& Hassan (1992) and Hassan et al., (1992) as:

$Q_{b}=L_{b} D_{s} W_{s}(1-P)$

Where $L_{b}$ is the mean annual rate of travel for bed material, $D_{s}$ and $W_{s}$ are the depth and width parameters of the active layer of the stream bed, and $P$ is the bed material porosity. Church and Hassan (1992) found that travel distances for individual size fractions relative to the travel distance for the $\mathrm{D}_{50}$ of surface material can be determined using the relation

$L=1.77(1-\log D)^{1.35}$

where $D$ is the ratio of the geometric mean size of the fraction of interest relative to the $\mathrm{D}_{50}$ of the subsurface material. As the tracer GSD used in the study only spans part of the observed GSD of channel bed material, equation 7 can be used to calculate the travel distances for size fractions outside of the range modelled by tracer stones. Using equation 6 , the resulting $Q_{b}$ can then be multiplied by the proportion of total sediment volume that a given fraction composes to determine the total volume of that size class which has been transported. Total bedload sediment flux $Q_{b t o t a l}$ in the study reach can then be calculated as

$Q_{\text {btotal }}=\sum_{i=1}^{n} Q_{b} F_{i}$ 
Where $F_{i}$ is the proportion of that sediment size class in the surface material, and $n$ is the number of fractions in the GSD.

\subsubsection{Change in channel bed storage}

To examine change in storage of settled fine sediment from field samples, the concentration of sediment in the collected samples was determined gravimetrically using vacuum filtration. Following Walling et al. (1998), the availability $\left(\mathrm{gm}^{-2}\right)$ of sediment on the channel bed can then be extrapolated from the concentration in samples multiplied by the volume of water in the sampling cylinder. The concentration result obtained at each sampling position was scaled up to incorporate the entire wetted channel based on field measurements, and extended halfway upstream and downstream from proximal sampling positions on the assumption that the storage of sediment is the same over this channel segment. Using this method, estimates of fine sediment storage within the wetted channel could be determined for the entire study reach at each time period, allowing for examination of temporal changes in storage of sediment on the channel bed.

Error in the estimate of fine sediment storage was calculated from the variability in samples collected at each cross section. At a given cross section, errors ranged from $20 \%$ of sample means at sites with homogenous beds to $100 \%$ of the sample means at sites with complex small-scale morphology.

Changes in channel storage of bedload sediment were examined through the comparison of topographic cross-sectional measurements collected one year apart. Positive vertical change between years indicates net storage increase, while negative change net decrease. 


\subsection{Suspended-sediment dynamics and SSC-discharge hysteresis}

To better understand the interaction between reach sediment balance components, temporal and spatial dynamics of suspended sediment were examined within the study reach. In particular, hysteresis in SSC-discharge relations can reveal information about suspended material dynamics and also the availability of fine sediment (Langois et al., 2005). To quantify this hysteretic behavior, the method proposed by Langois et al. (2005) and used by Hassan et al. (2014) was applied to data collected at the study reach outlet. For each event which contained suitable data, relations were developed between SSC and discharge during the rising and falling limbs of the flood peak. The ratio $H$ of the area under the rising-limb curve to the area under the falling limb curve was then calculated for each event separately. Langois et al. (2005) describes events with H $\sim 1$ as only weakly hysteretic, $\mathrm{H}<1$ as displaying counter-clockwise hysteresis, and $\mathrm{H}>1$ as displaying clockwise hysteresis. Of the 75 events during the 16 month study period where distinct SSC peaks were visible, only 20 met criteria outlined in Langois et al. (2005) for H-value calculation. Often, the hysteresis loops contained extended plateaus on the rising limbs, therefore generating robust regressions was not possible. Additionally, several events contained small subpeaks on the falling limb, which also affected SSC-discharge relations. 


\section{Chapter 4: Results}

We first briefly review hydrological and environmental conditions over the study period, followed by an examination of the character and availability of SS and the SSC-discharge relation at the reach inlet, outlet, and in ditch drainage channels. We then describe the compilation and components of the fine and bedload reach-scale sediment balances with a focus on the magnitude of road surface sediment input, and comparison to observed changes in fine material storage on the channel bed. Finally, temporal dynamics of sediment yields throughout the reach will be presented at the event and monthly-scale to help illustrate seasonal and event-based variability in road surface sediment contributions.

\subsection{Summary of hydrological and environmental characteristics during study period}

A summary of streamflow and rainfall for the study period are presented in Figure 4. The 16 month period from September $1^{\text {st }} 2012$ to December $31^{\text {st }} 2013$ was somewhat drier than average, with $1288 \mathrm{~mm}$ versus the $1980-2010$ average of $2050 \mathrm{~mm}$ recorded at the long-term climate monitoring station in Sandspit. Of this period, only the months of November 2012 and August and September 2013 recorded above-average precipitation; all other months were fairly dry in comparison to normal values. The driest months relative to the average were the typically wet months of March 2013 (43\% of normal), October 2013 (39\% of normal), and November 2013 (41\% of normal). At the Honna River mouth, total rainfall was 2103 mm, the wettest months being November 2012 (254 mm), February 2013 (216 mm) and December 2013 (260 mm). Sporadic snow cover was noted at the elevation of the study reach from late November 2012 until mid-January 2013, and 
again during December 2013, although not in great quantity. Mean annual river discharge at the
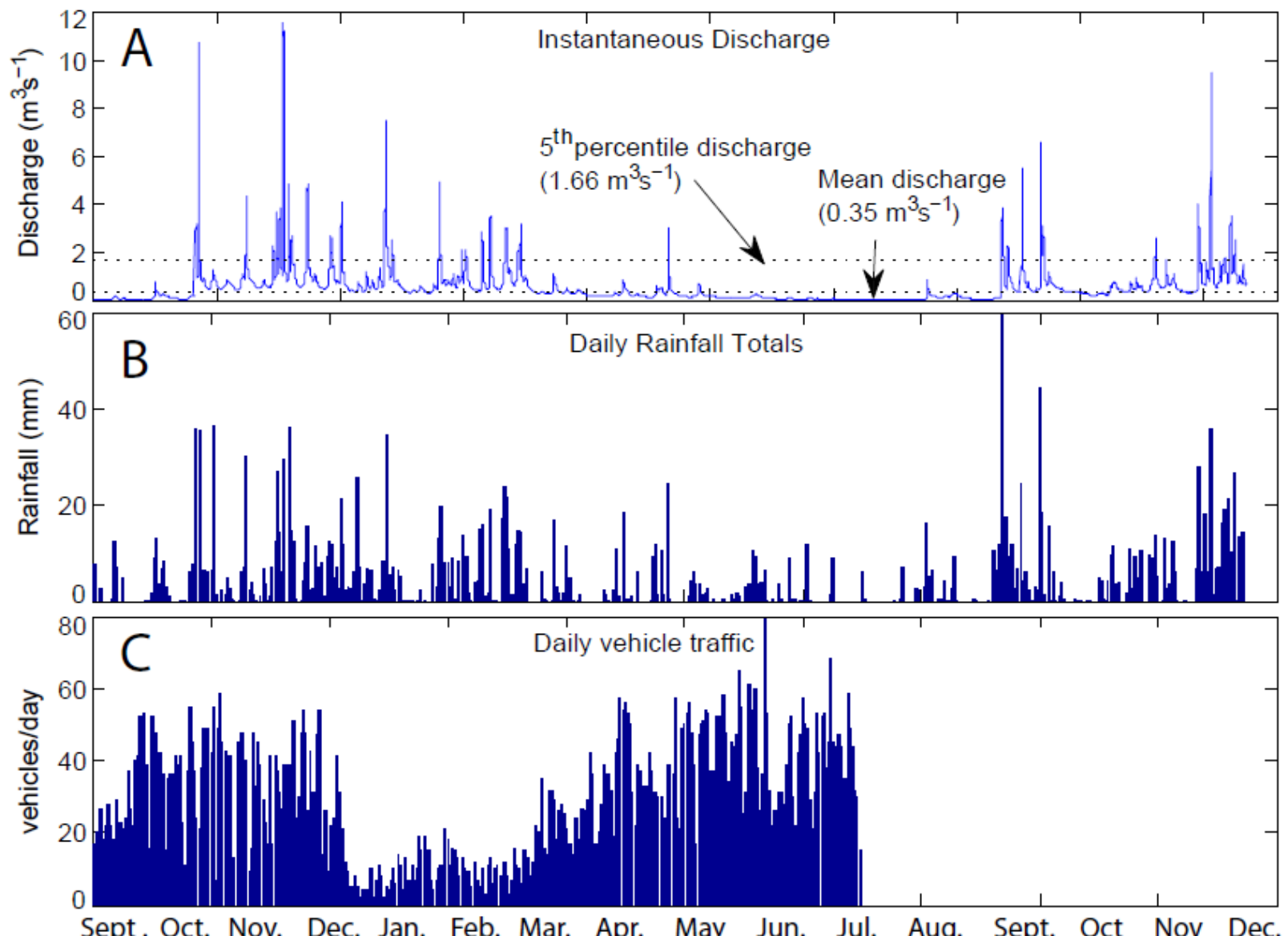

Figure 4: Instantaneous discharge (A), daily rainfall totals (B), and daily traffic totals (C) observed in the study reach over 16 month period.

reach outlet averaged $0.35 \mathrm{~m}^{3} / \mathrm{s}$, with $5^{\text {th }}$ percentile flows at $1.66 \mathrm{~m}^{3} / \mathrm{s}$. The maximum peak instantaneous discharge of $11.5 \mathrm{~m}^{3} / \mathrm{s}$ occurred on October $15^{\text {th }}, 2012$, following a moderate rainstorm where $51 \mathrm{~mm}$ was recorded in 36 hours. Overall, 32 discharge events occurred where the $5^{\text {th }}$ percentile flow was exceeded by the peak "storm" flow.

Traffic volume over the period was seasonally variable. Monthly totals of vehicle passes ranged from a high of 1378 in May, 2013, to a low of 245 in February 2013. Low traffic volumes in the winter months correspond to road closures at locations of high elevation, and a lack of 
industrial activity. Ongoing problems with traffic recording equipment led to an absence of traffic data after July $20^{\text {th }}, 2013$. Several road maintenance activities were undertaken adjacent to the study reach: road grading occurred in October 2012 and July 2013, snow plowing in December 2012, and a bridge crossing the upstream Skowkona tributary was replaced in May 2013.

\subsection{Event scale suspended-sediment concentration dynamics}

The cumulative grain size distributions (GSD) of SS from the study reach and ditch drainage channels are presented in Figure 5. The $\mathrm{D}_{90}$ of suspended material found in ditch channels was 0.1 $\mathrm{mm}$, and for material in the river, $0.5 \mathrm{~mm}$. In addition to the smaller $90^{\text {th }}$ percentile grain size of the suspended sediment transported from the road surface, differences in GSDs between the two sample collection areas were notable.

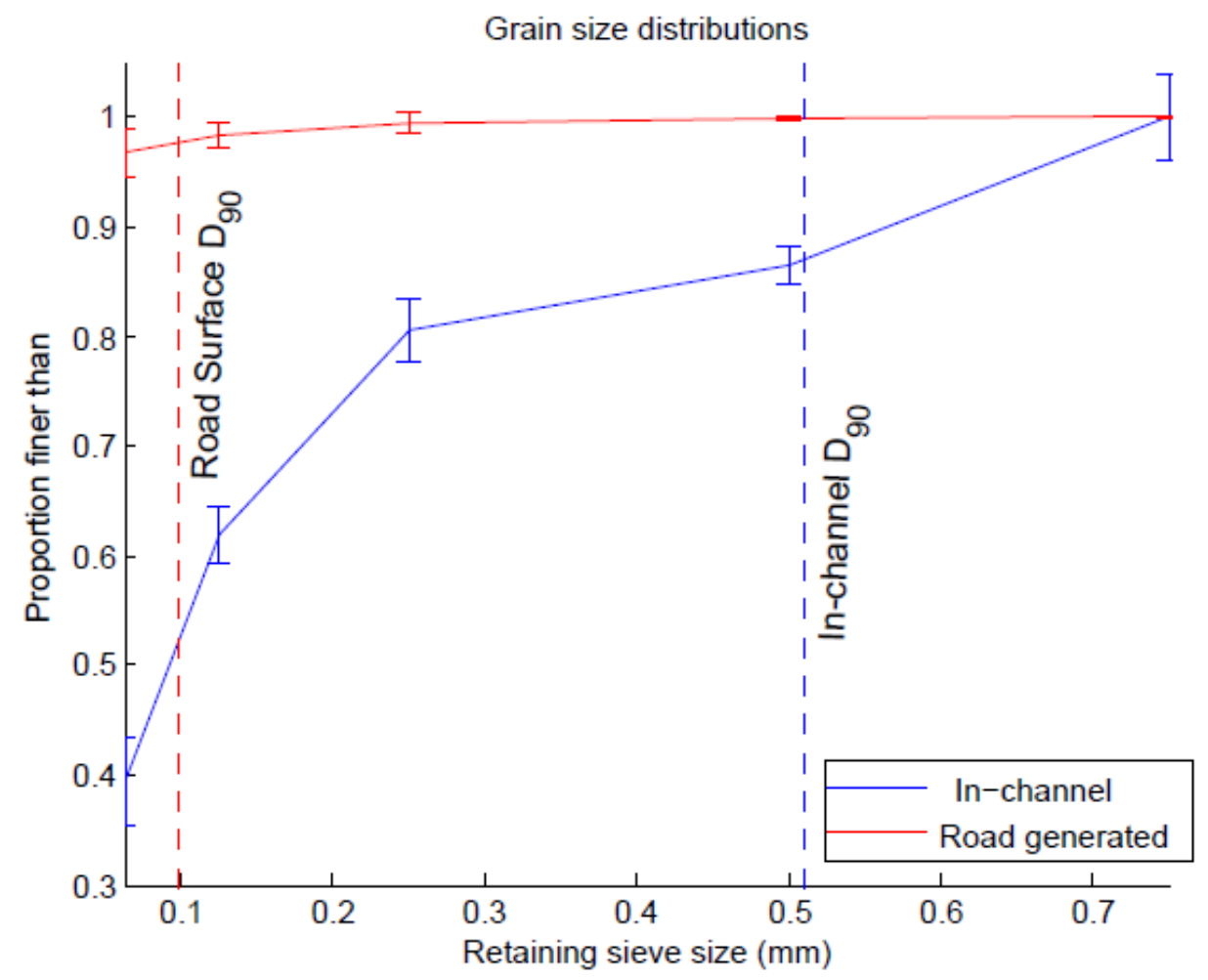

Figure 5: Grain size distribution (GSD) of suspended material found in the main channel and in ditch drainage channels. 
For example, suspended material collected in ditch drainage channels and the main channel was $97 \%$ and $39 \%$ finer than $0.063 \mathrm{~mm}$, respectively. Almost no material was found to be greater than $0.5 \mathrm{~mm}$ in diameter in the ditch drainage channels, while nearly $14 \%$ of suspended material in the river exceeded $0.5 \mathrm{~mm}$.

Inspection of SSC-discharge relations reveal hysteretic behavior during nearly all events both in-channel and in ditch drainages. Example discharge-SSC hysteresis plots representing events on November $21^{\text {st }}, 2012$ and August $18^{\text {th }}, 2013$ at the reach inlet, outlet and DD3 drainage are presented in Figure 6. The DD3 site was selected to represent other ditch drainages as it contained the highest-quality dataset and most well-defined SS events, and SSC-discharge dynamics were found to behave in a similar way to the other drainage channels. $\mathrm{H}$ values at the reach upstream inlet and downstream outlet are positive and greater than 1 during both events, indicating that clockwise hysteresis and sediment supply limitations are present. $\mathrm{H}$ values within the main channel are much higher during the summer than winter event $(\mathrm{H} \sim 8.5$ vs. $\mathrm{H} \sim 2.0)$ suggesting greater sediment depletion in the wet season. $\mathrm{H}$ values for the ditch drainage channel were slightly below and slightly above 1 in November and August, respectively, indicating weaker overall hysteretic behavior. Within the main river channel, peaks in SSC arrived before peak discharge during the November event, but in August correspond more closely to peak discharge.

Clockwise hysteretic behavior was observed in relations between SSC and discharge for all sediment flux events in the main river channel over the study period (Figure 7A). $\mathrm{H}$ values calculated for sediment entering the channel from the DD3 drainage were more variable, with several values close to or below 1. Although the dataset is limited, it seems possible to separate in-channel $\mathrm{H}$ values into two groups based on seasonality: 5 events correspond fairly closely with 
the drier, low flow season (April to September) and the remaining with the high flow season (October to the end of March). $\mathrm{H}$ values during seasonally low-flow conditions displayed more exaggerated hysteresis, ranging between 4.1 and 7.5, while those in the wetter part of the year were more moderate, ranging between 3.4 and 1.1.

For DD3, the $\mathrm{H}$-values range from 0.8 to 8.8 , greater than the range observed in the main channel, and DD3 values do not appear to follow as clear a seasonal pattern. A negative relation with discharge was found within the main river channel (Figure 7B), with the highest $\mathrm{H}$ values associated with low peak flows. No clear relation exists between $\mathrm{H}$ value and discharge in the ditch drainage channel, however.

In addition to hysteretic behavior, notable differences in SSC duration curves were observed between in-channel and ditch-drainage sediment monitoring stations. The duration curves for SSC in the main channel and ditch drainages are presented in Figure 8. For in-channel measurements, the only sediment concentration that occurred more than 5\% of the total time was that at or below $10 \mathrm{mgl}^{-1}$. In contrast, concentrations of $10 \mathrm{mgl}^{-1}$ or less occurred between 8 and $22 \%$ of the time in water emanating from ditch drainage channels. This discrepancy continues with increasing concentration: for values of $100 \mathrm{mgl}^{-1}$, water entering and leaving the reach exceeds this value less than $0.1 \%$ of the time, whereas for ditch drainage channels, the $100 \mathrm{mgl}^{-1}$ threshold is exceeded between 0.5 and $3 \%$ of the time. Maximum observed concentrations were much higher for ditch drainage channels relative to in-channel values, ranging from 340 to $450 \mathrm{mgl}^{-1}$, in comparison to 75 and $120 \mathrm{mgl}^{-1}$ for the upstream and downstream reach stations, respectively. 

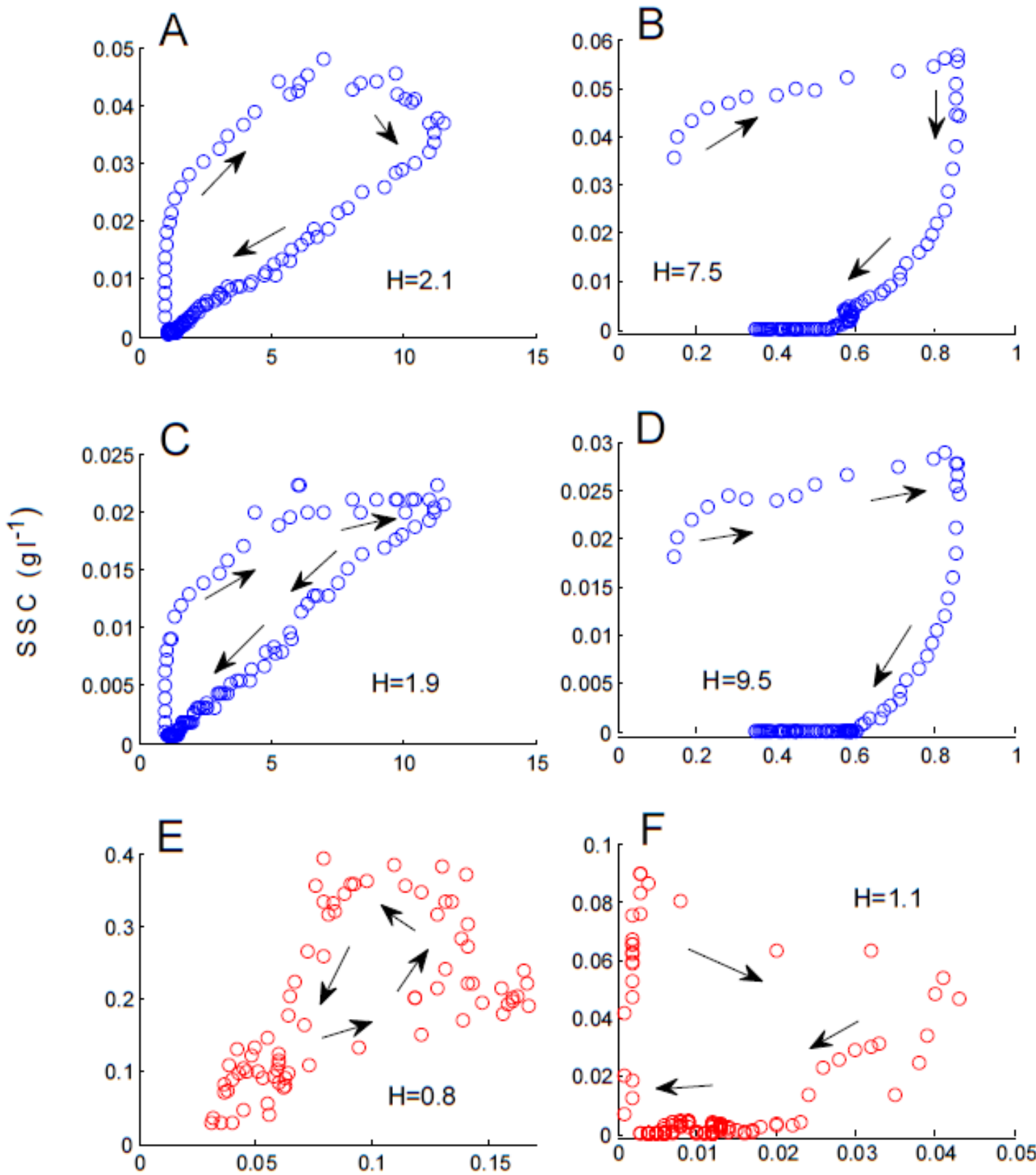

Discharge $\left(m^{3} s^{-1}\right)$

Figure 6: Relations between SSC and discharge during events on November $21^{\text {st }} 2012$ and August $18^{\text {th }} 2013$, at the reach outlet $(A, B)$, reach inlet $(C, D)$, and DD3 ditch drainage channel $(D, E)$. Arrows indicate direction of hysteresis. 

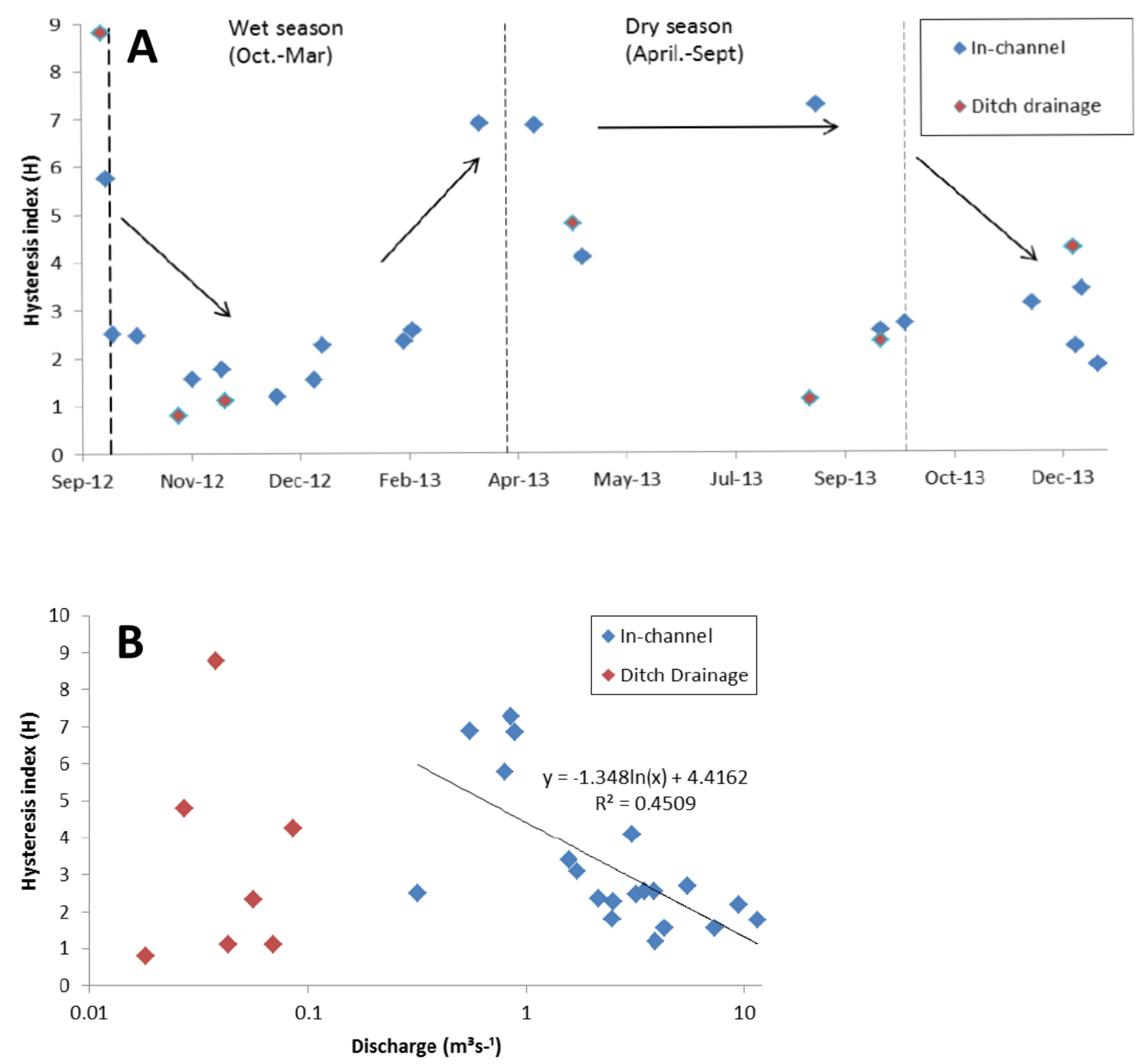

Figure 7: A: Comparison of $\mathrm{H}$ value over time in the main channel and in DD3 ditch drainage. B: Relation between discharge and $\mathrm{H}$ value in the main channel and DD3 ditch drainage. No fit line was plotted through DD3 points as no trend was observed. 


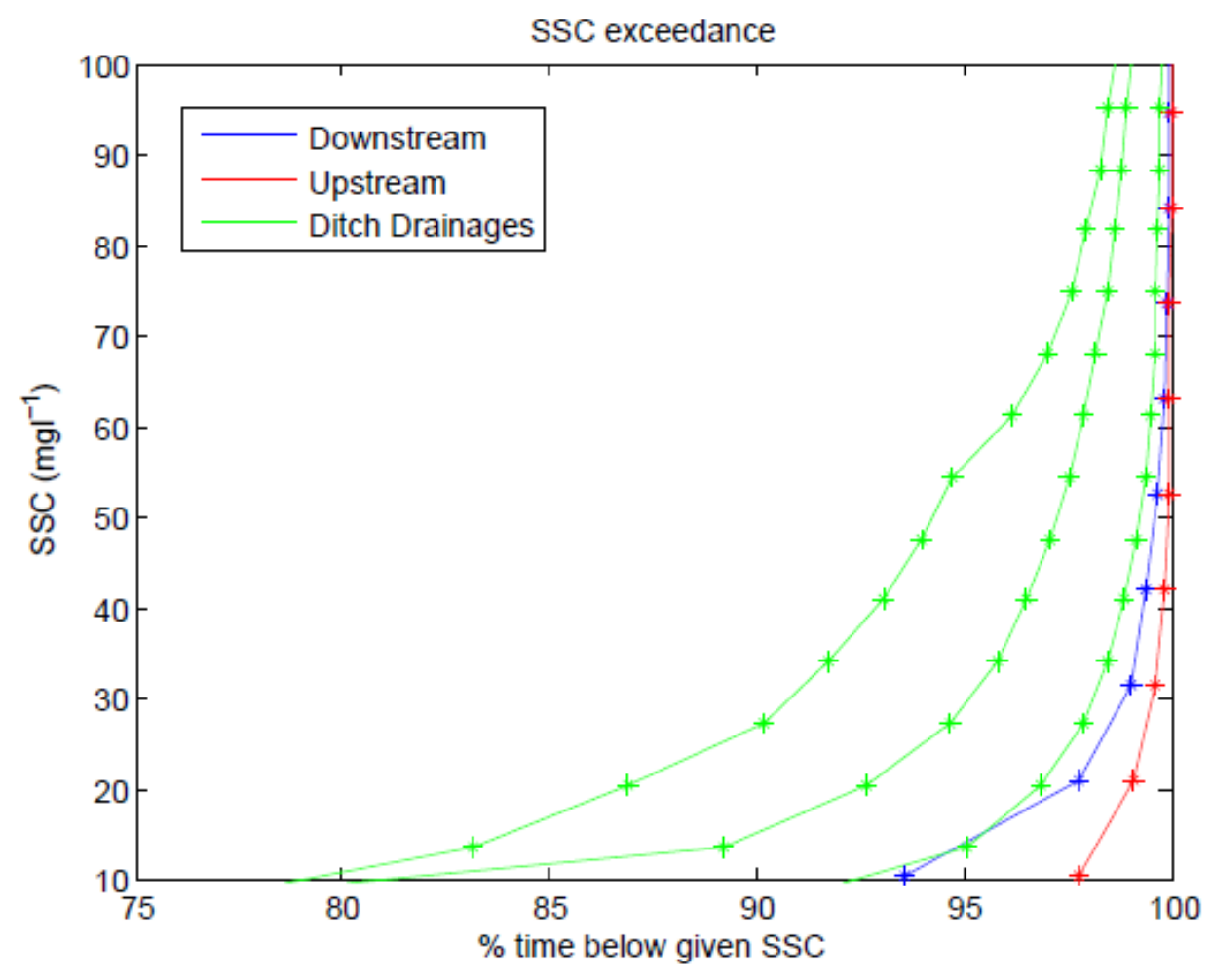

Figure 8: Cumulative exceedance of suspended sediment concentrations at the reach inlet, outlet, and at all three instrumented ditch drainage channels.

Differences in SSC exceedance within the reach also translate to varying numbers of discrete events of elevated SSC. At the reach inlet, 100 events occurred where baseline SSC was exceeded by $3 \mathrm{mgl}^{-1}$, while at the reach outlet, 125 events occurred, and within ditch drainages, 233 events were recorded. Often, two or even three small events would occur during the ditch drainages over the course of a more attenuated event in the main channel, illustrating the more rapid response times of the ditch drainage systems. At the upstream reach inlet and downstream outlet, median peak event concentration was 8 and $9 \mathrm{mgl}^{-1}$, respectively, while in ditch drainage channels, the median event SSC was notably higher, at $22 \mathrm{mgl}^{-1}$. 


\subsection{Reach scale sediment balance for 12 month period - Sept 2012 to Sept 2013}

\subsubsection{Suspended-sediment balance}

A summary of the reach-scale SS balance from September $1^{\text {st }} 2012$ to September $1^{\text {st }} 2013$ is presented in Figure 9. Total annual fine sediment yield from the reach was calculated to be $72.6 \pm$ 23.2 tons. For this same period, $49.7 \pm 17.8$ tons of sediment was delivered to the reach from upstream. Total combined contribution from the ditch drainages was $14.1 \pm 4.3$ tons, most of which entered the main channel from DD1 and DD3.

In terms of bank erosion, analysis of cross-sectional profiles and erosion pin data yielded fairly modest retreat rates: the erosion rate as determined from the comparison of channel profiles yielded an average retreat rate of $1.6 \pm 5.9 \mathrm{~cm} / \mathrm{yr}$. The high uncertainty in retreat rate results from high variability in individual measurements, and also the comparatively low measurement resolution used when collecting field data.

\section{Reach-scale suspended-sediment balance}

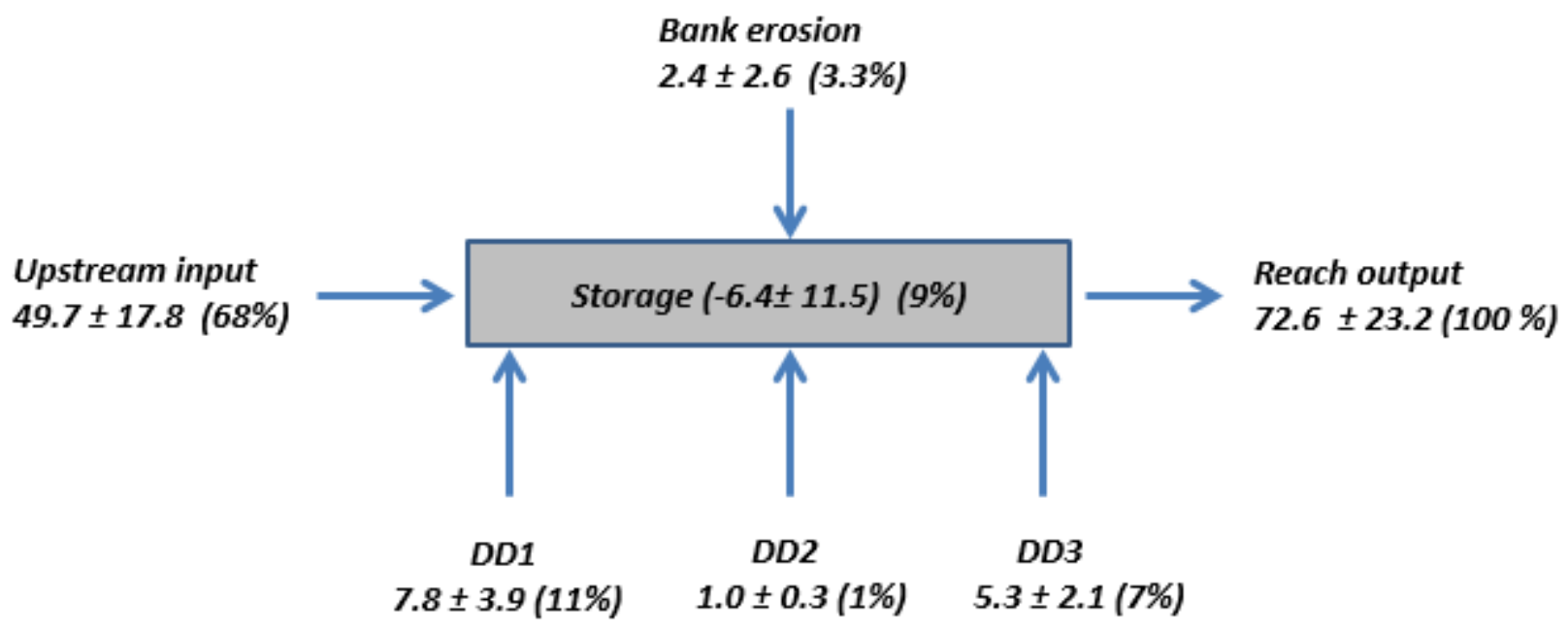

Total road input $14.1 \pm 4.3(19 \%)$

Figure 9: Components of reach-scale fine sediment balance, in tons. Note negative storage value. 
Retreat rates determined from bank erosion pin measurements were somewhat higher at $3.3 \pm 2.2 \mathrm{~cm} / \mathrm{yr}$, expected given their placement in locations of apparent erosion.

Combined, these results yield an average retreat rate of $2.1 \pm 4.1 \mathrm{~cm} / \mathrm{yr}$. The total volume of sediment introduced to the stream was determined to be $9.6 \mathrm{~m} 3 / \mathrm{yr}$, given an average measured bank height of $60 \mathrm{~cm}$ and $775 \mathrm{~m}$ of erodible channel banks, which scales to $4.08 \mathrm{~m}^{3}$ per kilometer of channel. Using a bulk density factor of $1.6 \mathrm{~g} / \mathrm{cm}^{3}$ and a fine-sediment proportion of $16 \%$, this erosion yields a total annual input mass estimate of 2.4 tons of sediment $<0.35 \mathrm{~mm}$.

As proportions of material leaving the reach, upstream SS input composed $68 \%$, collective ditch drainage channels $19 \%$, and bank erosion $3 \%$. Unaccounted for in this balance is 6.4 tons, or just under $10 \%$ of the material leaving the reach. In terms of within-reach sediment sources, road surface material dominates at $62 \%$ of total inputs, with bank erosion at $10 \%$.

\subsubsection{Bedload sediment balance}

Tracer stone recovery, travel distance, and burial depth characteristics are presented in Table 4. The greatest transport distances were in the order of 60 meters from the deployment position, where several tracers had settled on a large bar just upstream of a channel-blocking log jam. Most stones remained on the surface, with only $21 \%$ of recovered stones found sub-surface. Average burial depth of subsurface tracers was $4.6 \mathrm{~cm}$ with the most deeply buried stones found within 25 $\mathrm{cm}$ of the surface, suggesting that the active layer is fairly shallow in this channel. Figure 10 shows a plot of measured and calculated $L / D$ ratios for each size fraction. Observed travel distances plot closely over the predicted ones, lending confidence to our extrapolation of transport rates for grain size fractions not included within the tracer study. 


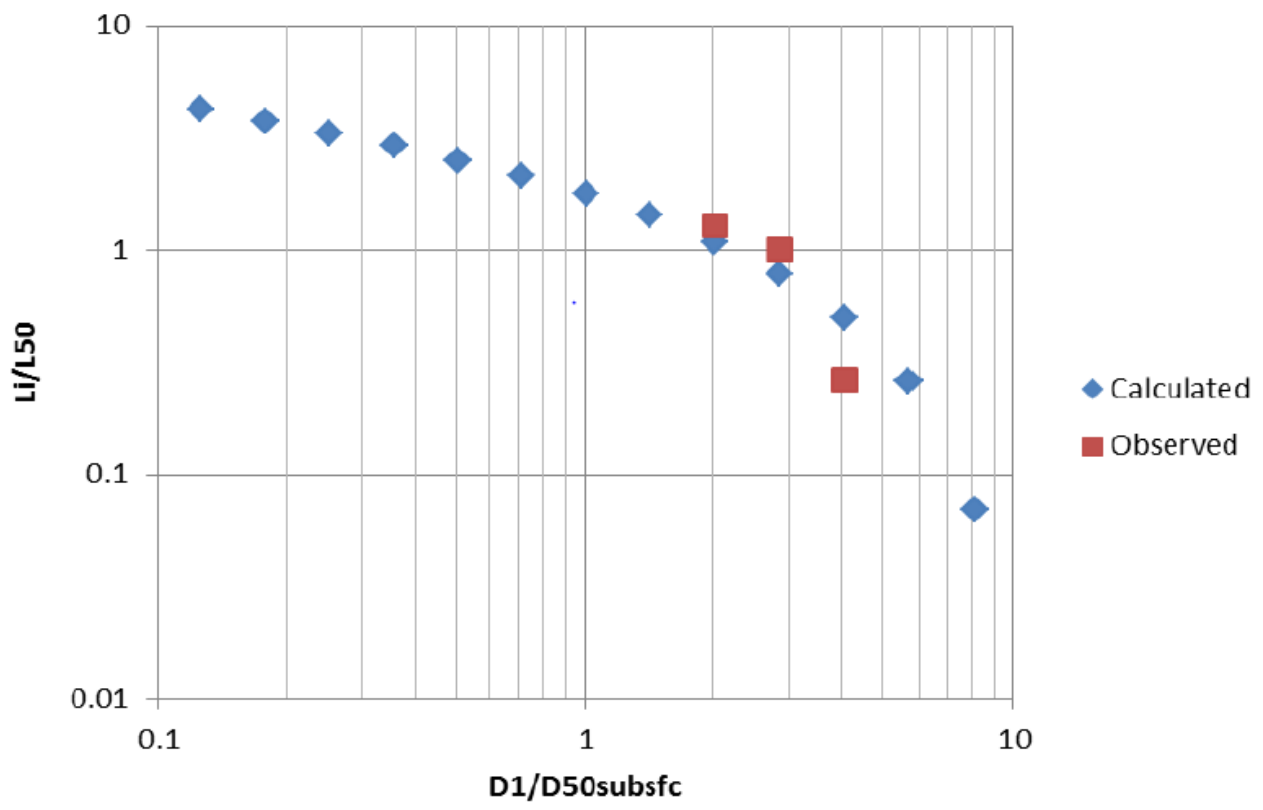

Figure 10: Relation between scaled particle distance and scaled particle size for observed and predicted sediment size fractions.

As bedload sediment input and output to and from the reach was not measured directly, transport within the reach is assumed to provide an approximation of the quantity of material likely to enter and leave the reach during the same period. The majority of bedload material transport during the 2012-2013 water year appears to have occurred during the two largest flooding events on October $15^{\text {th }}$ and November $20^{\text {th }}, 2012$, with respective peak discharges of 10.8 and 11.5 $\mathrm{m} 3 / \mathrm{s}$. These events were with peak rainfall intensities of 7.4 and $5.4 \mathrm{~mm} / \mathrm{hr}$, , respectively, and event rainfall totals of 34.4 and $29.4 \mathrm{~mm}$. Following the fractional transport rate methods described, total bedload sediment volume transported was calculated to be in the order of $7.6 \mathrm{~m}^{3}$ over the one-year study period. Using a bulk density for fluvial gravels of $1.6 \mathrm{~g} / \mathrm{cm}^{3}$, the total bedload sediment flux mass was calculated to be $12.9 \pm 13.9$ tons, about $15 \%$ of the total sediment flux for the study period. 
Table 4: Bedload tracer stone characteristics and recovery statistics.

\begin{tabular}{lllllllll}
$\begin{array}{l}\text { Stone } \\
(\mathrm{mm})\end{array}$ & size & $\mathrm{N}$ & $\mathrm{N}$ recov. & $\begin{array}{l}\text { Recovery } \\
\text { Rate }(\%)\end{array}$ & $\begin{array}{l}\text { mobile } \\
\text { mon travel }\end{array}$ & $\begin{array}{l}\text { Max travel } \\
\text { distance }(\mathrm{m})\end{array}$ & $\begin{array}{l}\text { Mistance }(\mathrm{m}) \\
\text { buried }\end{array}$ & $\begin{array}{c}\text { Mean burial } \\
\text { depth }(\mathrm{cm})\end{array}$ \\
\hline Total & 340 & 292 & 86 & 69 & 15.3 & 62 & 21 & 4.6 \\
$<64$ & 65 & 60 & 92 & 73 & 4.18 & 32.9 & 28 & 4.6 \\
$<45$ & 125 & 109 & 87 & 78 & 15.9 & 62 & 17 & 2.6 \\
$<32$ & 150 & 123 & 82 & 61 & 20.5 & 60.1 & 27 & 5 \\
\hline
\end{tabular}

\subsubsection{Measured change in sediment storage}

To examine changes in the storage of fine sediment, plots of the mean scaled sediment storage values are presented in Figure 11. The application of t-tests for means determined that winter and summer storage values are significantly different, but differences between the two summer collection periods are not.

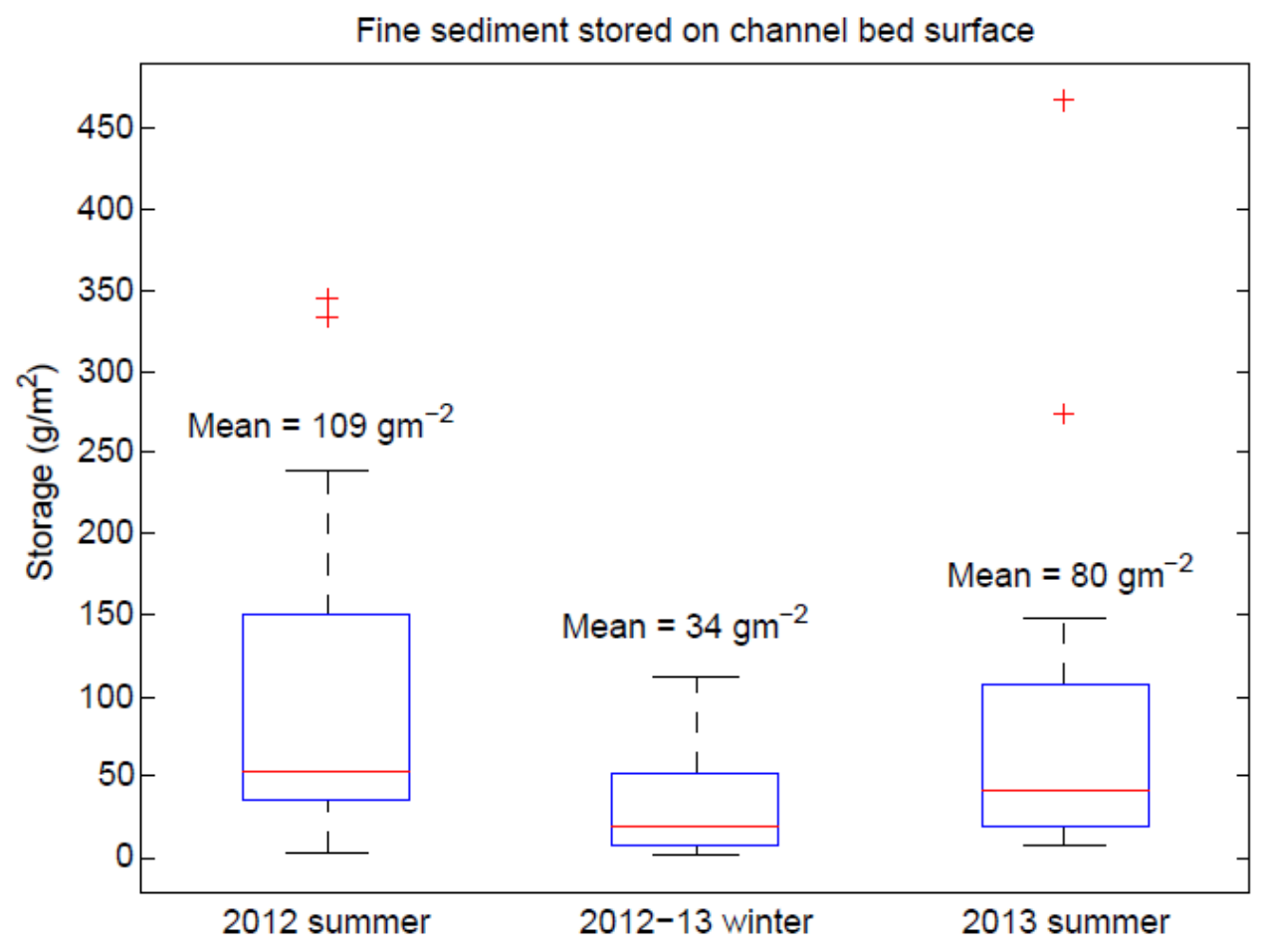

Figure 11: Availability of fine sediment on the reach channel bed during August 2012, February 2013, and July 2013. 
Scaled storage values were highly variable at and between channel cross sections, much of this variability likely attributable to differences in local water velocities in pools and riffles or behind obstructions. Applying storage values for individual cross sections to wetted channel area for each sampling period yielded total fine sediment storage masses of $223 \mathrm{~kg}$ for September 2012, $102 \mathrm{~kg}$ for February 2013, and $197 \mathrm{~kg}$ for July 2013, small quantities relative to the total sediment flux in the reach. Storage values were not applied to dry channel areas since a visual inspection of gravel surfaces yielded no evidence of fine sediment accumulation, but backchannels, pools, and other wet areas disconnected from the main channel were sampled and included in the storage estimate.

Net change in bed elevation along the study reach between August 2012 and July 2013 was found to be within measurement errors at all but two cross-sections, and averaged to a net bed elevation increase of less than $1 \mathrm{~cm}$. As measured change in bed elevation is very small, and since the input of eroded bank material closely matches the bedload flux rate within the reach, net change in bedload material storage within the channel is considered negligible between the two measurement periods.

\subsection{Spatial and temporal patterns of suspended sediment dynamics over 16 month period}

\subsubsection{Event-scale dynamics}

Normalized cumulative water and sediment yields totaled from individual events reveal differences between sediment dynamics in-channel and in ditch drainages. Cumulative water yields at the reach inlet, outlet, and for combined ditch drainages are presented in Figure 12. A slope in the water-sediment yield $>1$ indicates relatively rich sediment supply, and $<1$ a poor 


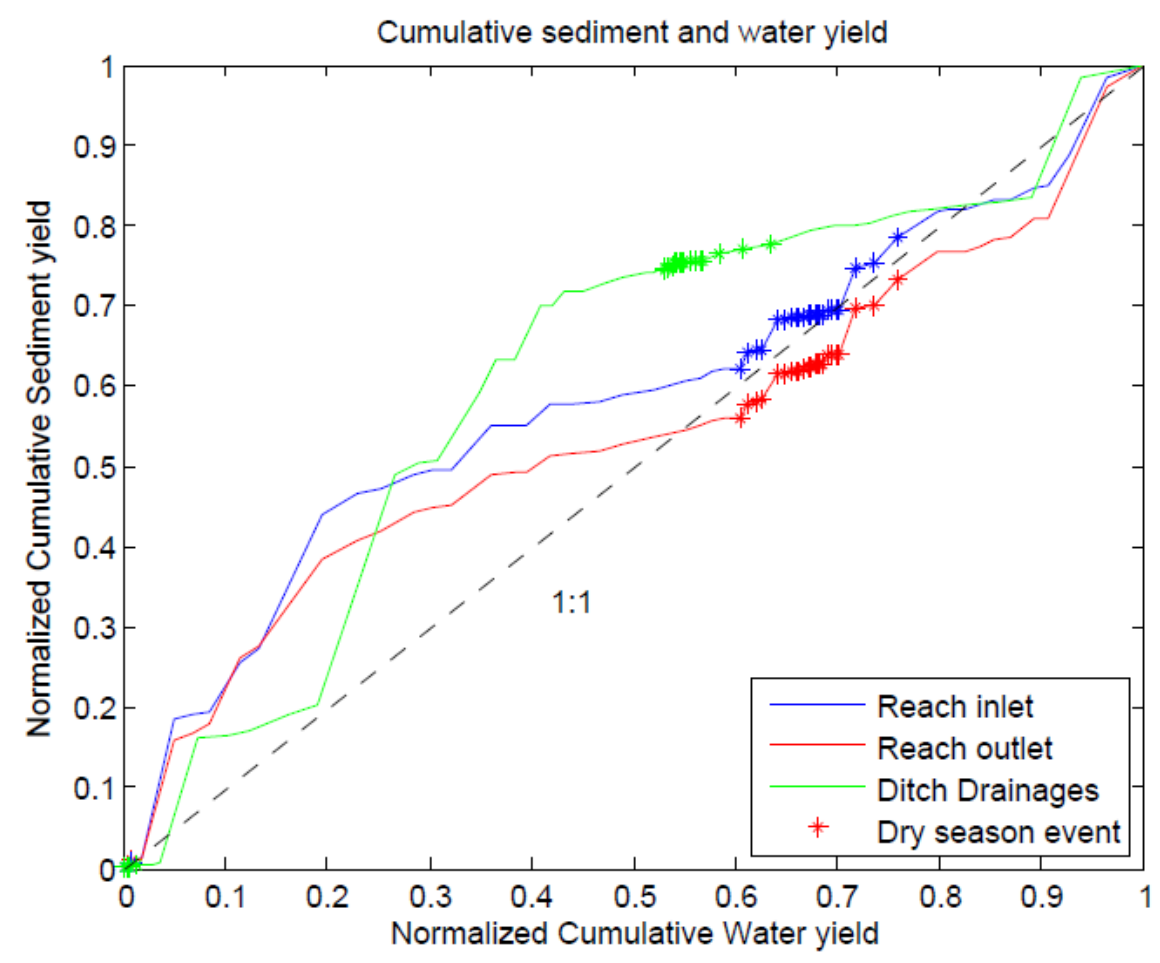

Figure 12: Cumulative yields of water and sediment at the upstream reach inlet, reach outlet, and collective ditch drainages.

sediment supply. Similar patterns are observed at the reach outlet and upstream inlet, with a steeper slope ( 2) occurring during the fall months, and then a reduction in slope ( $\sim 0.6)$ in later winter and early spring months. During the seasonally dry period from April 2013 to the end of September 2013, the slope of the relations is close to 1 , and then steepens with the succeeding fall. The relation for ditch drainage channels is similar, with a slope of $\sim 1.7$ persisting until spring months, at which point the slope flattens to $\sim 0.3$. Unlike the upstream input and downstream output sites, sediment availability of ditch drainage flow remains limited through the dry months, and the relation does not steepen until later in the fall.

Sediment flux and gains/losses for individual events in the reach and ditch drainage channels are presented in Figure 13. Sediment yields over the 16 month period at the downstream reach outlet, 
upstream inlet, and from the three ditch drainages were, respectively, 104.2, 77.8, and 18.6 tons. The most active periods of sediment flux occur from mid-October to late November 2012, and again near mid-September and December 2013. The dry period from May to the end of August was comparatively inactive, with $16 \%$ of sediment transport events and only $5 \%$ of total sediment flux occurring. Within the main channel, the largest event, with a peak rainfall intensity of 7.2 $\mathrm{mm} / \mathrm{hr}$ occurred during a rainstorm on October $15^{\text {th }}, 2012$, where $14 \%$ of the total 16 month suspended yield was transported through the reach. Collectively, the three largest events mobilized $33 \%$ of the total 16 month yield, with the remaining events accounting for $77 \%$ of total yield. The largest single event contribution of combined road surface sediment inputs occurred on November $20^{\text {th }}, 2012$, and introduced 4.4 tons of material to the channel. The three largest road surface sediment input events corresponded to the three largest events at the reach outlet and upstream inlet, but combined account for $52 \%$ of the total road input, proportionately more of the total than within the main channel.

Per-event net gains/losses in stored sediment appear generally related to the magnitude of the reach outlet sediment yield (Figure 13). With the exception of a handful of events in October 2012 and December 2013, events yielding more than 2 tons of sediment are associated with net loss from the reach, while smaller events $<2$ tons or with a peak discharge $<3 \mathrm{~m}^{3} \mathrm{~s}^{-1}$ correspond with net sediment gain. September - December 2012 and January - March 2013 are dominated by events associated with net loss. In the April-August period, only two events correspond with net loss, while the remaining 18 events lead to net positive sediment accumulation, expected given low water velocities conducive to the settling of fine material. Persistent sediment accumulation is also observed during the drier than average period in October to early November 2013, and the 4 month block averages to net positive storage. 


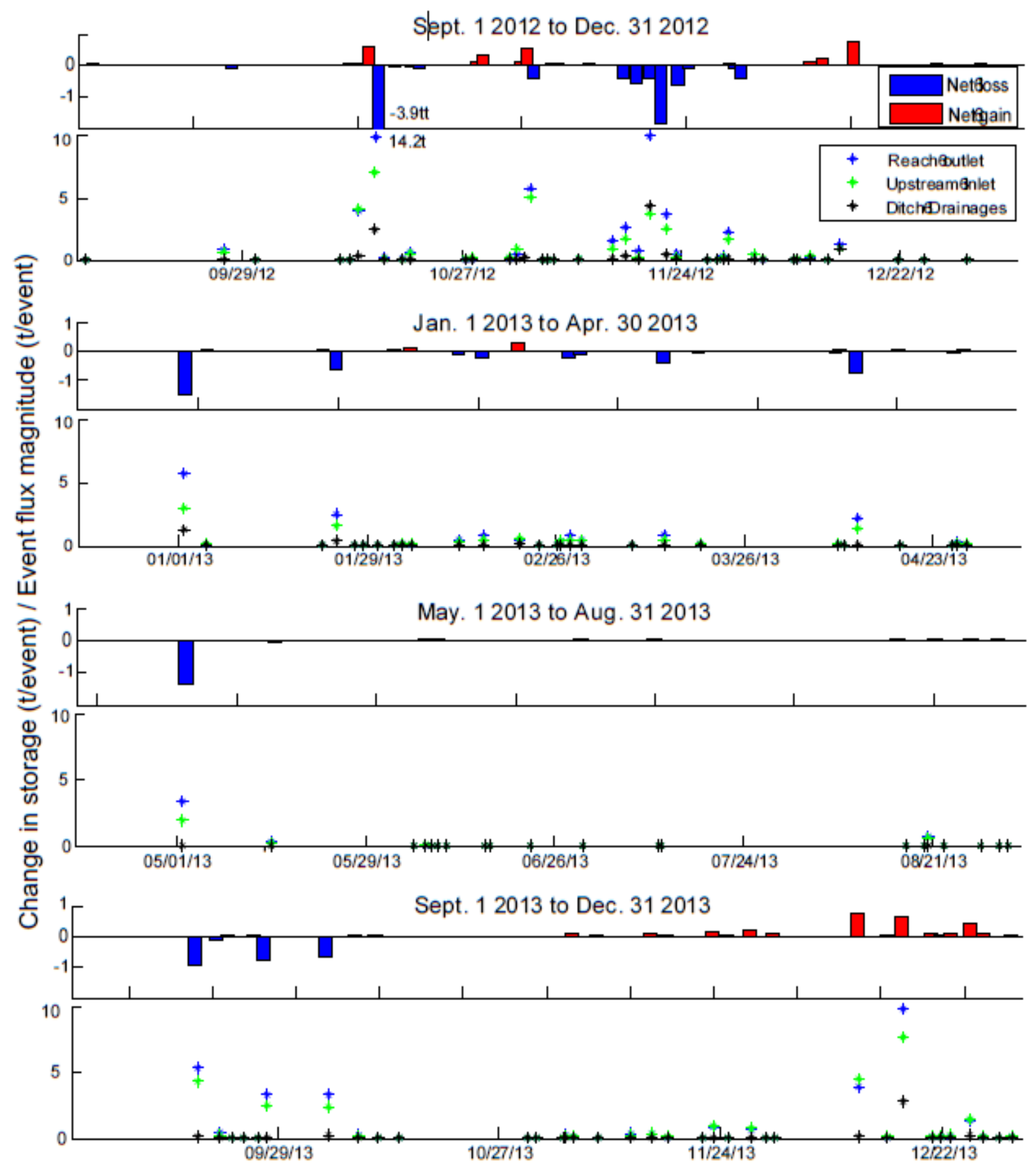

Figure 13: Plots of net sediment gains and losses per event, and per-event total yields of sediment at the reach inlet, outlet, and ditch drainage channels. The $\mathbf{1 6}$ month data record is presented here in four blocks of four months each. 
Totals of sediment entering and leaving the study reach during each event are presented in Figure 14A. Input sediment includes material from upstream and from ditch drainage channels. The relation between input and output appears generally linear and most points are close to the 1:1 line, with scatter increasing with event magnitude. Periods of smaller flux plot slightly above the line, implying net sediment deposition in the reach during these times. Conversely, larger events plot on or below the 1:1 line, suggesting that net sediment loss is occurring from the reach. The slope of the relation is 0.81 , indicating that on average; slightly more sediment is leaving the reach than is accounted for in the specified inputs. The three events of largest flux are plotted notably distant from the main body of points, and correspond to large floods on October $15^{\text {th }}$ and November $16^{\text {th }}$ 2012, and December $16^{\text {th }} 2013$, all with peak flows exceeding $10 \mathrm{~m}^{3} \mathrm{~s}^{-1}$. Although dominated by the two weeks with the largest sediment flux, a weak negative linear relation between $\Delta S$ and output is observed in Figure 14B. Excluding the two events of largest sediment flux, a significant negative relation still persists with a slope of $-0.15(t=-8.1, p<.001)$, again suggesting greater net sediment loss during periods of larger flux.

Several outlying points are visible on Figure 14B. Point (1) is associated with unusually high net positive storage given the magnitude of the sediment flux event. This point corresponds with an event occurring on December $14^{\text {th }}, 2012$ after a significant snowfall had occurred at the reach elevation; plowing of snow from the road surface may have loosened additional road sediment and agitated settled material in ditches. This is reflected by the high $(>50 \%)$ proportion of road surface sediment relative to total inputs for this event. Point (2) is associated with the greatest net loss of sediment from the reach, plotting well below the fit line. This event corresponds with the largest observed sediment flux in the reach occurring on October $15^{\text {th }}, 2012$, and also the date of a major wind storm which blew down several large trees close to the channel. The major 

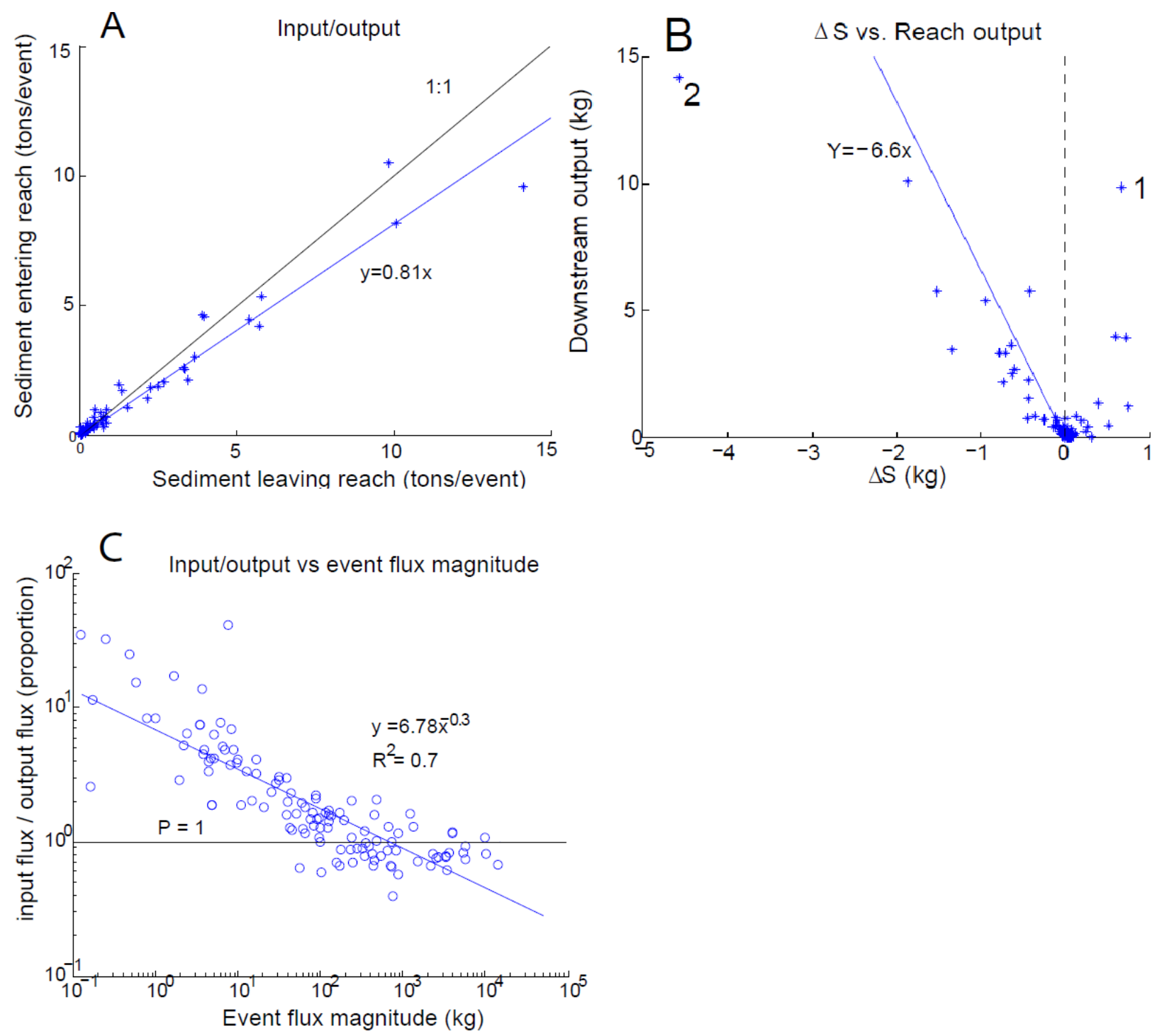

Figure 14: A: comparison of per-event collective reach input vs output. B: Comparison of change in net sediment storage vs reach output. Note highlighted points 1 and 2 in figure. C: Ratio of inputs/outputs vs total sediment flux from the reach.

negative storage observed during this event may be a result of bank erosion input, destruction of bed surface armoring, overbank flooding, or tree throw from blowdown.

The tendency for total sediment input to exceed output appears inversely related to event flux magnitude (Figure 14C): the input/output proportion for events yielding more than 1 ton of 


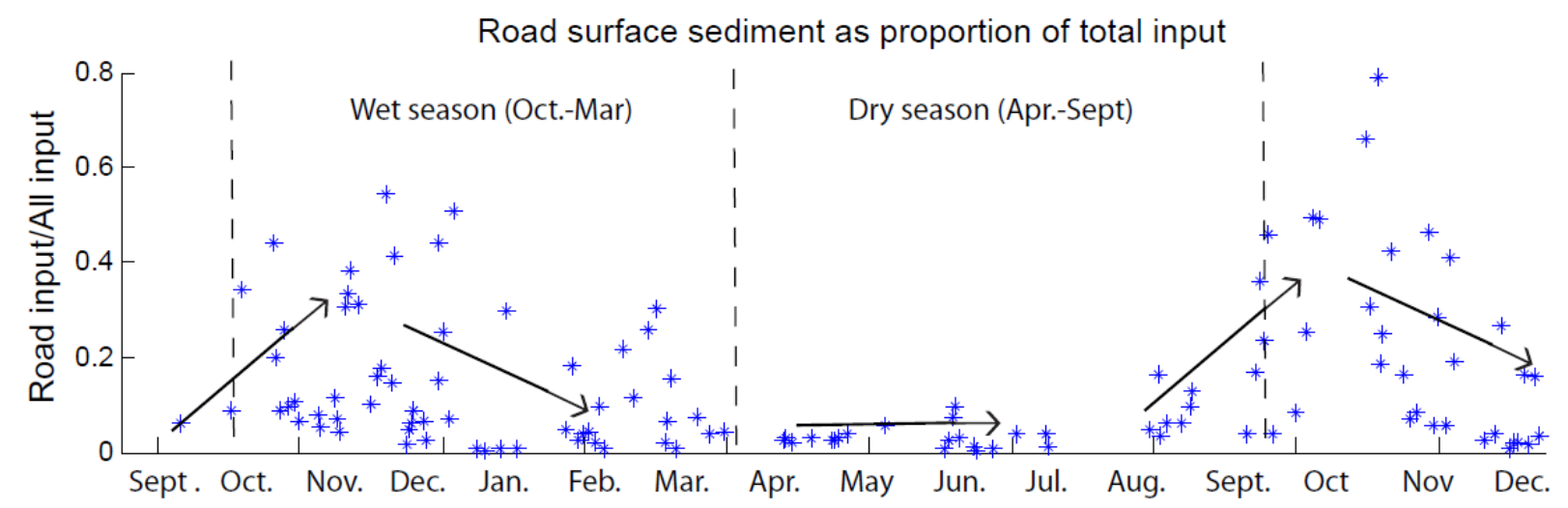

Figure 15: Road surface material as a proportion of total inputs to the reach over the 16 month period.

material is close to or below 1 , is scattered between 0.6 and 2 for events between 1 and 0.1 tons, and for small events $<0.1$ ton, ranges from 1 to 24.8 . This again points to net accumulation of material during inactive conditions, and the opposite during periods of high flux.

The proportion of road surface sediment relative to total reach input is presented for each event in Figure 15. As a proportion of total input, road surface sediment averaged $15 \%$, with a maximum of $80 \%$ in November 2013, and minimum of 0.2 in July 2013\%. Proportions were consistently below $10 \%$ during the dry period of April-September, but regularly exceeded this same threshold during the wetter half of the year. Values were fairly consistent during the dry period, with little variation. In comparison, the proportion of road surface material entering the reach during wet periods displayed significantly more variation. 


\subsubsection{Month-scale dynamics}

Monthly gains/losses in in-channel fine sediment, total sediment yields, and road surface sediment as a proportion of total inputs are presented in Figure 16. Monthly flux at all sites were highest in the month of November 2012, where 28.3, 17.9, and 6.2 tons of sediment passed, respectively, the reach outlet, upstream inlet, and collective ditch drainage channels. As a proportion of total flux, this translates to 27,23 , and $33 \%$, respectively. The least active month was July 2013 , where less than $1 \%$ of the total flux passed each site. Net sediment loss was observed from the reach during all months but December 2012, June-August 2013, and November-December, 2013. The greatest change in storage corresponds with net loss occurring during November 2012, and greatest gain in December 2013.

As a proportion of total sediment input, road surface input follows the event scale pattern discussed above. The greatest proportion of 0.4 occurred during December 2012, while the lowest occurred during late spring and summer months, with a minimum of 0.02 in August 2013. Precipitation peaked in winter months, with the highest values falling in November 2012 and December 2013, with 270 and $280 \mathrm{~mm}$ falling during those months, respectively. Summer months, as expected, were comparatively dry, with very little rain falling in July 2014.

This trend is also reflected in mean monthly discharge, which is highest during fall and winter months, and lowest in the summer. Discharge in July, 2014, is particularly low, associated with observed settling of fine sediment on the channel bed. A significant quantity of snow was observed falling in the study reach during December 2012. Traffic data is incomplete for the last 6 months of the overall period, but highest values are observed during summer months, and lowest values in winter, a result of road closures and limited industrial activity. 

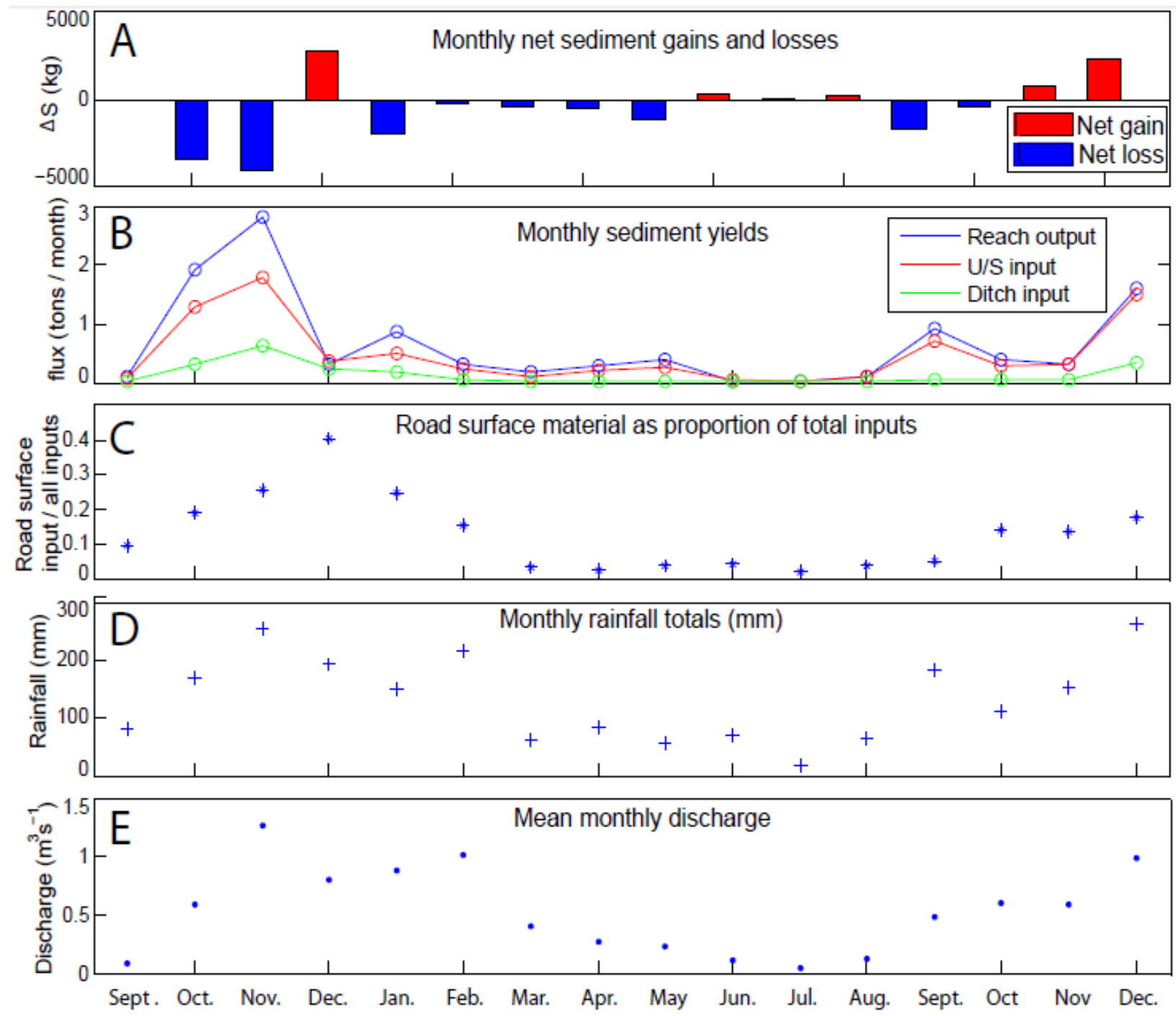

Figure 16: A: month-scale net sediment gains and losses. B: Monthly sediment flux at reach inlet, outlet, and from collective ditch drainages. C: Road surface material as a proportion of all inputs during each month. D: Monthly rainfall totals. E: Mean monthly discharge 


\section{Chapter 5: Discussion}

\subsection{Project overview}

In this study, a reach-scale sediment balance was developed for a segment of the main stem of the Honna River, B.C., to examine the spatial and temporal dynamics of sediment contributions from an unpaved resource road to the main river channel. Balance components in this reach include sediment from upstream, sediment leaving the reach downstream, material input from bank erosion, and sediment input from a forest road surface. Yields of the sediment balance components are presented at the annual scale, while dynamics of suspended sediment load were examined at the event and monthly scale over a 16 month period. Analysis of the SSC-discharge relation in the main channel and in ditch drainages was used to investigate patterns in sediment availability, and the effect of road surface sediment on temporal availability trends.

\subsection{Road surface material as a reach-scale sediment balance component}

Over the period of interest for the balance (12 months), the majority of sediment entered the reach from upstream, followed by contributions from the road surface and minor input from bank erosion. The value of road surface sediment mass proportional to total flux ( 19\%) falls towards the middle of the range of road surface contributions reported in the literature at the basin scale (Reid et al 1981; Motha, et al, 2003; Gruszowski, et al, 2003; Baird, 2011). The contribution of bank erosion to the reach is relatively low but within the range of values reported in the literature for forested banks in the Pacific Northwest (Lehre, 1982; Roberts \& Church, 1986). Much of the sediment entering the reach from upstream may also consist of road surface material: two ditch 
drainage channels located within 300 meters of the reach upper limit were observed contributing material to the main channel, with spot measurements indicating a 90 NTU increase in turbidity downstream of one drainage channel input during a summer event. No studies appear to have directly investigated the reach-scale contribution of road surface sediment to streams relative to natural sources, but these results suggest that road surface sediment can be locally dominant, in the case of the Honna River study reach, exceeding input from bank erosion by a factor of 5 .

Although not a part of the fine sediment balance, bed material transport characteristics can help place other reach balance components within the framework of the total sediment load passing through the system. Of the total sediment load (suspended and bed) in the reach for the 12 month period, bedload flux constitutes $15 \%$ of all material by mass; as measurements were conducted over a relatively short timescale, significant uncertainty surrounds bank erosion measurements and bedload transport rate calculations, and these values may represent overestimates of the quantity of bed material passing through the system. If bedload material is included, the relative contribution of road surface sediment then drops from 19 to $16.5 \%$. The majority of bedload transport likely occurred during two events in the fall of 2012, which are also associated with large suspended sediment yields. As long-term flow monitoring in the basin does not exist, the return period of such events is difficult to assess. Several studies (Paustian and Beschta, 1979; Kurashige, 1994; Hassan et al, 2005a) have found that substantial quantities of fine sediment are stored below the channel bed surface in streams with bed surface armoring. Although the scour depth indicated through recovered tracer stones in the study reach is fairly shallow and peak flood events only just achieved bankfull depth, it is possible that periods of bedload sediment mobilization and local destruction of the armour layer could introduce additional fine sediment to the water column. 
Although the measured balance terms account for $90 \%$ of the sediment leaving the reach, the measured change in storage is much smaller than the inferred change. The $10 \%$ of material not accounted for is within the errors of the other balance terms, but other sediment sources and sinks may exist. On several occasions, road surface sediment was observed entering the study reach main channel through subsurface flow, suggesting that even non-channelized road runoff could elevate SSC in proximal rivers. Given the small distance between road and river and highly hydraulically conductive soils in the region, this could potentially explain much of the unaccounted for sediment in the balance. Other possible sediment sources in the reach include the release of sediment from behind logjams (Beschta, 1979), windthrow from tree blowdown (Gomi et al, 2005), and disturbance from animal crossings (Buckhouse, 1981; Kondolf, 1983, reported in Gomi, et al 2005).

The inferred changes in sediment storage correspond well to the field measurements of fine sediment settled on the channel bed. The magnitude of measured fine sediment storage change between low and high flow periods (i.e. summer, winter) is small, less than one ton along the reach. Peak storage densities in summer $\left(109 \mathrm{~g} / \mathrm{cm}^{2}\right)$ are very low in comparison to those reported in Lambert and Walling, (1988), Walling et al (2006), and Lopez-Tarazon et al (2012), likely a result of differences in basin geology and fine sediment sources within the watershed. Low storage values in the summer months may also be a result of the mismatch between high sediment input volumes and flow conditions which permit the settling of SS. Streamflow during the period of noted sediment accumulation rarely exceeded $0.5 \mathrm{~m}^{3} \mathrm{~s}^{-1}$, with only one event exceeding $1.0 \mathrm{~m}^{3} \mathrm{~s}^{-1}$. When water velocities are low enough to permit sediment settling, sediment input is also limited, therefore few opportunities exist for sediment to accumulate in great quantity on the channel bed, findings similar to those discussed by Bilby et al (1989) and Lane and Sheridan (2002). Road 
surface sediment does appear to enter the study reach during the low flow season and therefore likely elevates material storage quantities above natural levels, but this contribution appears transient and relatively minor when compared to non-road sediment sources.

Although the QC Main road runs parallel to the main-stem of the river for six kilometers, varying width of flat areas adjacent to the channel, discharge, and road connectivity characteristics mean that local road contributions are likely to vary substantially along the channel length, making extrapolation of reach-scale results difficult.

\subsection{Effective contributing road area and hydrogeomorphic connectivity}

The QC Main forest road contributes substantial quantities of sediment to the reach even though only $\sim 20 \%$ of the road area is directly coupled to the main river channel. These findings suggest that in the absence of a floodplain or with more frequent drainage channels, road surface sediment could enter the stream in much larger quantities. Although not entirely connected by drainage channels, the entire road area drains onto erodible flat areas adjacent to the active river channel; additional road-derived sediment may enter the reach in the future if the Honna River migrates laterally towards the road embankment. Conversely, migration away from the road could lead to reduced input.

As observed in other streams by Duncan et al. (1987), sediment contributions from individual coupled ditch drainages in the study reach are not even; DD1 and DD3 both contribute more than five times as much sediment as DD2, even though their contributing areas are, respectively, 2.3 and 0.9 times as large. Along the QC Main, differences in sediment contribution from individual drainages could be related to variation in ditch blocking and vegetation (Luce and Black, 1999), drainage channel length and slope (Dietrich \& Anderson, 1998; Duncan et al., 1987), 
road surface slope (Luce and Black, 1999), and local supply of fine sediment (Sheridan and Noske, 2007; van Meerveld et al, 2014). Specifically, ditch block depth appears somewhat greater adjacent to the DD2 road drainage area, likely limiting input of sediment to the channel during rainfall events which would be capable of introducing sediment to DD1 and DD3.

Models used to estimate the production of road surface sediment usually include contributing road area as a key input parameter (e.g. Anderson and MacDonald, 1998; Ketcheson et al 1999; Costantini et al, 1999; Ziegler et al, 2001; Ramos-Scharron and MacDonald, 2007): these findings suggest that without considering how much of the road surface effectively contributes sediment to streams, such models may not serve as useful tools to predict the actual quantity of material likely to enter streams. Findings from the Honna River study reach suggest that models including total road area as a primary variable in sediment yield predictions may overestimate the input of material unless the effect of the hydrogeomophic connection between road and river is known. Further research related to factors affecting sediment delivery to streams would help improve the utility of such models.

\subsection{Availability and dynamics of suspended-sediment}

The greater exaggeration of hysteresis observed in the SSC-discharge relations in the main channel than in DD3 (Figure 6) suggests that relative to streamflow, less fine sediment is available for transport in the main channel than in the ditch drainage channels. Compared to the strong clockwise hysteresis observed in the main channel during both events, SSC-discharge hysteresis in the DD3 drainage channel is more modest, and even runs slightly counter-clockwise during the November event. Instances of absent or counter-clockwise hysteresis may be a result of ditch blocking adjacent to the road surface: during certain conditions, the bulk of the sediment may not 
enter ditch drainage channels until sediment-rich water has overtopped ditch blocks. Along the study reach, ditch blocks and ditch drainage channels appear to be fairly effective at trapping road surface sediment: SSC as measured leaving the road during simulated rainfall experiments by van Meerveld et al (2014) were, at times, an order of magnitude higher than SSC observed in monitored ditch drainage channels during events of similar rainfall intensity. The modest $\mathrm{H}$ values and suggested high availability of sediment in ditch drainage channels differ from the supply limitation observed on the QC Main surface during sprinkler experiments in van Meerveld et al (2014), who noted rapid declines in the SSC of road runoff following the initiation of rainfall. Differences in the timing of road surface runoff and mixing in ditch blocks may explain the lack of hysteresis in the drainage channels.

Both cumulative water and sediment yield (Figure 12) and $\mathrm{H}$ value (Figure 7A) reveal similar trends in sediment availability in the main channel, with a replenishment of sediment during the low flow season, and a decline in availability over the wet season with successive events, a phenomenon also noted in several other studies (Paustian \& Beschta, 1979; Sidle \& Campbell, 1985; Asselman, 1999). The seasonal differences in $\mathrm{H}$ value and apparent relation to river discharge in-channel (Figure 7A and 7B) are reasonable given the tendency for greater sediment accumulation in dry periods, but other studies such as Langois et al. (2005) have not observed a clear relation between flow characteristics and $\mathrm{H}$ value. The lack of a clear relation between discharge and $\mathrm{H}$ value in the DD3 channel suggests that sediment supply limitations relative to streamflow are not as prevalent.

The high $\mathrm{H}$-values in the main channel during the dry season correspond to periods when a greater supply of fine sediment relative to flow conditions is found on the channel bed (see Figure 11). Even though relatively abundant, fine sediment stored on the channel bed is still mostly 
depleted during the rising limb of storm events, and therefore has the effect of increasing rising but not falling limb sediment yields. This further exaggerates the hysteretic SSC-discharge relation; the positive relation between sediment availability and $\mathrm{H}$ value has also been noted by Langois et al (2005). Although road surface sediment contributions are relatively minor in summer months (Figure 15), this added sediment is likely to settle on the channel bed along with non-road material, leading to greater observed H-Values during periods of persistent low flow.

During both the low and high flow seasons, road surface sediment contributions may also serve to moderate clockwise hysteresis in the main channel: the more modest or absent hysteresis observed in road runoff may add proportionately more sediment to the main channel falling hydrograph limb. For example, the slightly lower $\mathrm{H}$ values observed at the reach outlet compared to inlet during the November $21^{\text {st }}$ and August $18^{\text {th }}$ events may be a result of road sediment input. Shorter-scale changes in sediment availability could occur as a result of differences in peak SSC between the main channel and ditch drainage channels during storm events: as peaks and subpeaks in road surface storm runoff SS yield do not always correspond with peaks in the main channel, advanced or delayed peaks in road surface runoff contributions could serve to, respectively, exaggerate or dampen hysteresis in the SSC-discharge relation in-channel. Given that nearly twice as many events were recorded in ditch drainage channels compared to the main river channel, this effect appears plausible.

The greater proportion of total time that streamflow exceeds a given SSC at the reach outlet compared to the inlet is a likely consequence of the input of sediment from the road surface given the significantly higher SSC in road surface runoff. Elevated in-channel SSC and turbidity as a result of point-source road surface sediment is widely reported anecdotally, but has been quantified in few studies: Bilby,( 1985), Lane and Sheridan (2002), Baird, (2011) and Thomaz et al, (2013) 
found that road surface sediment led to elevated turbidities or SSC downstream of the road runoff point of entry.

\subsection{Temporal dynamics in road surface sediment contributions}

The contribution of road surface material changes in tandem with seasonal variation in event flux magnitude in both relative and absolute terms. Given the low infiltration capacity of unpaved road surfaces, the relatively minor input of road surface material during the dry period from April to the end of September was unexpected. Some studies (e.g. Bilby, 1985; Duncan et al, 1987) suggest that the ease with which road surfaces produce runoff would lend them to be relatively greater sediment sources during dry periods, as more precipitation is required to elevate streamflow and mobilize sediment in the main channel than on compacted roads. Additionally, the lower frequency of major rainfall events and greater quantity of vehicle traffic during the dry season would serve to maintain a supply of fine material available for transport on the road surface. In the case of the Honna River study reach, the relatively minor contributions of road surface sediment during the low flow season may be a result of ditch design and ditch blocking. Although sufficient runoff may be generated in summer months to transport sediment from the road surface, much of this material may be captured in empty ditch blocks before it can travel to the main stream channel. Additionally, the absence of the road-cut induced baseflow observed in ditch drainage channels during wet periods may lead to greater storage of road surface material within these channels, further reducing the quantity of material delivered to streams.

The months of December 2012 and November and December 2013 are of interest as the proportion of road surface material input relative to other inputs is fairly high during numerous events, and net positive storage of fine sediment is observed within the main channel. Examination 
of sediment inputs to the December 2012 events revealed that upstream inputs to the reach were relatively normal, and the net positive storage appears mostly attributable to road material input. During this period, rainfall intensities were not notably high (>30 mm/24 hrs), and vehicle passes were below average. As previously discussed, plowing of snow from the QC Main in midDecember 2012 may have disturbed road surface material, introduced sediment-rich snow into ditch drainage channels, and may have agitated settled material within ditch blocks, leading to abnormally high contributions of sediment to the main channel. During November and December 2013, road surface contributions were above average, but the net increase in storage appears related to input entering the study reach from upstream. Subsequent field investigations in March 2014 revealed that a major channel avulsion had taken place around a log jam 100 $\mathrm{m}$ upstream of the study reach, eroding substantial quantities of floodplain material. This channel change and local increase in sediment availability in close proximity to the study reach may explain the positive storage of material observed during November and December 2013 events.

\subsection{Implications of findings for land managers}

Findings in this study suggest that locally, road surface material is a major source of sediment to streams, contributing substantially more material than riparian erosion in the reach of interest. The interaction between the Honna River and the QC Main forest road represents scenario with a high potential for sediment input from resource road surfaces, but efforts to mitigate the quantity of sediment leaving the QC Main surface have been made through the use of ditch blocks, vegetation, and strategic placement of culverts. Such mitigation efforts appear critical in restricting the input of sediment during the low flow season, when water quality and habitat are particularly sensitive to added fine material. The road area effective for contributing sediment to the main river channel 
is small relative to total road area, a finding which needs to be considered when using road sediment production models to assess contributions to streams. As the contribution of sediment from the road surface was not as apparent in areas de-coupled from the main channel, careful placement of roads away from stream channels and dispersion of runoff to avoid channelization could help reduce the input of road surface material to streams. In the case of the Honna River, road-relocation may be the best way to reduce input of surface sediment to the main river channel. The reach-scale results presented in this study may prove additionally useful if they can be extrapolated to the basin scale. Once rates of riparian sediment input, change in fine material storage, and flows required to mobilize bedload material are known, inputs from tributaries can be subtracted and the remaining sediment attributed to non-natural sources. In the Honna River, the close coupling of road to channel extends along much of the main stem, suggesting that road surface material is likely a major component of the suspended load even at the river mouth. 


\section{Chapter 6: Conclusion}

The objectives of this study were to examine the contributions of road surface sediment to a reachscale sediment balance of the Honna River, B.C, with a focus on spatial and temporal dynamics of road material input. These objectives were met through the establishment and monitoring of a road-affected reach of the Honna River, whereby reach inputs, outputs, and change in sediment storage were measured directly over a one year period, and suspended-sediment dynamics over a 16 month period. From analysis of collected field data, the following conclusions can be drawn:

- Road surface sediment contributed $19 \%$ of the total fine sediment yield at the reach outlet, compared to $68 \%$ from upstream and 3\% from bank erosion. Change in measured storage of fine sediment was negligible between the two summer periods, but was significantly lower in winter. Bedload material comprised $\sim 15 \%$ of the total sediment yield over the 12 month period.

- Only $20 \%$ of the road surface was directly coupled to the river channel, as the remaining road area was decoupled as a result of floodplain geometry and road design. The nature of the connection between road and river is critical in determining the quantity of sediment delivered to river channels from road surfaces, and the effective contributing road area is much less than total road area adjacent to the reach.

- Suspended material transported from the road surface was finer than that found in the main channel. Clockwise hysteresis was observed during all events in the river channel, implying limited sediment availability relative to streamflow. Hysteresis is weak or absent in road- 
surface runoff, and $\mathrm{H}$ value does not appear related to discharge as is seen in the main channel. The greater number of SSC events and higher overall SSC at the reach outlet compared to the reach inlet suggests that road surface sediment is elevating SSC in the main channel.

- At both the event and month-scale, periods of high sediment flux are associated with net sediment loss from the reach, while periods of lower flux occur in association with sediment deposition. The seasonally dry period (April to September) was associated with slight net positive storage, while the wet season (October-March) with net negative storage, with the exception of December 2012 and November and December 2013. A slight but significant negative relation exists between event-scale reach sediment output magnitude and change in storage.

- As a proportion of total fine material input to the reach during periods of elevated SSC, road surface sediment ranges from less than $5 \%$ to greater than $70 \%$. The proportion was highly variable during the wet season, but was consistently below $10 \%$ during the dry season. This may be a result of ditch blocking preventing road runoff from small rainfall events from entering drainage channels.

- Road surface material appears likely to settle in the main channel during low flow conditions, but in small quantities relative to settling of non-road material, and accumulated fine material is quickly evacuated during high-flow conditions. In-channel storage values are overall quite low compared to values reported in the literature. 
This study provides the only known attempt to quantify the input of road surface sediment at the reach scale in relation to natural sediment sources. However, several limitations exist with this study design and location. Perhaps most importantly, reach-scale results do not necessarily reveal meaningful information about basin-scale processes: additional research will be required to accurately assess the relative contributions of road surface material at the watershed scale. As with any observational study, the window of observation may not be representative of general conditions. For this project, conditions were abnormally dry, and a lack of long-term hydrological data led to difficulties in placing our study conditions in the context of average values. Finally, it is difficult to fully capture all reach balance terms. In this balance, several terms were not feasible to measure, and may have contributed significant quantities of sediment.

Several additional research opportunities exist to improve the body of knowledge surrounding the contributions of road surface sediment to streams. Although empirical, an examination of downstream changes is road surface contributions along rivers would lead to an improved understanding of the scale-dependency of the significance of these inputs. A better understanding of how road-river connectivity and effective drainage area affect sediment yields to streams would undoubtedly help improve models used to predict sediment delivery. Finally, an investigation of the effects of road use, maintenance, and different sediment-input mitigation strategies on road sediment yield to streams would prove beneficial. 


\section{Bibliography}

Asselman, N. (1999). Suspended sediment dynamics in a large drainage basin: the Rhine River. Hydrological Processes, 13, 1437-1450.

Baird, E., Floyd, W. C., \& van Meerveld, H. J. (2012). Road Surface Erosion pt. 2: Assessment of the Water Quality Effectiveness Evaluation Method for the Honna River Watershed, Haida Gwaii. Streamline, 15(1), 8pp.

Baird, E., \& Schmidt, M. (2011). Controls on sediment generation from forest roads in a pacific maritime watershed. MSc Thesis, Simon Fraser University.

Beschta, R. L. (1978). Long-term patterns of sediment production following road construction and logging in the Oregon Coast Range. Water Resources Research, 14(6), 1011. doi:10.1029/WR014i006p01011

Bilby, R. (1985). Contributions of road surface sediment to a western Washington stream. Forest Science, 31(4), 827-838. Retrieved from http://www.ingentaconnect.com/content/saf/fs/1985/00000031/00000004/art00009

Bilby, R., Sullivan, K., \& Duncan, S. (1989). The generation and fate of road-surface sediment in forested watersheds in southwestern Washington. Forest Science, 35(2), 453-468.

Brown, K. R., McGuire, K. J., Aust, W. M., Hession, W. C., \& Dolloff, C. A. (2014). The effect of increasing gravel cover on forest roads for reduced sediment delivery to stream crossings. Hydrological Processes, 12 pp. doi:10.1002/hyp.10232

Bruton, M. N. (1985). The Effects of Suspendoids on Fish. Hydrobiologia, 125, 221-241.

Canada, E. (2014). Canadian Climate Normals 1981-2010 Station Data. Climate Normals and Averages. Retrieved from http://climate.weather.gc.ca/climate_normals/results_1981_2010_e.html?stnID=367\&autof wd=1, February $16^{\text {th }}, 2014$. 
Church, M., \& Hassan, M. (2005). Upland gravel-bed rivers with low sediment transport. JAWRA Journal of the American Water Resource Association, 14, 2780-2785

Church, M., \& Hassan, M. A. (1992). Size and Distance of Travel of Unconstrained Clasts on a Streambed. Water Resources Research, 28(1), 299-303.

Costantini, A., Loch, R. J., Connolly, R. D., \& Garthe, R. (1999). Sediment generation from forest roads: bed and eroded sediment size distributions, and runoff management strategies. Soil Research, 37, 947-64. Retrieved from http://www.publish.csiro.au/?paper=SR98088, February $19^{\text {th }}, 2014$

Croke, J., Hairsine, P., \& Fogarty, P. (1999). Sediment Transport, Redistribution, and Storage on Logged Forest Hillslopes in South-Eastern Australia. Hydrological Processes, 13, 27052720 .

Curry, R. A., \& MacNiell, W. S. (2004). Population Level Responses to Sediment During Early Life in Brook Trout. Journal of the North American Benthological Society, 23, 140-150.

Dietrich, W. E., \& Anderson, N. H. (1998). Dynamics of Abiotic Parameters and Sediment Retention in Summer-dry Headwater Streams of Western Oregon. Hydrobiologia, 379(1-3), $1-15$.

Dietrich, W. E., \& Dunne, T. (1978). Sediment Budget for a Small Catchment in Mountainous Terrain. Z. Geomorph. N. F, 191(206), 190-205.

Dobson Engineering Ltd. (1996). Honna River Watershed, results of the coastal watershed assessment procedure (pp. 550-604). Kelowna.

Duncan, S., Bilby, R., Ward, J. W., \& Heffner, J. T. (1987). Transport of road surface sediment through ephemeral stream channels. JAWRA Journal of the American Water Resources Association, 23(1), 113-119.

Dunne, T., \& Leopold, L. (1978). Water and Environmental Planning (p. 818). San Francisco. 
Eaton, B., Hassan, M., \& Phillips, J. (2008). A Method for Using Magnetic Tracer Stones to Monitor Changes in Stream Channel Dynamics. Streamline, 12(1), 7pp.

Gadgil, A. (1998). Drinking water in developing countries. Annual Review of Energy and the Environment, 23, 253-286. Retrieved from http://www.annualreviews.org/doi/pdf/10.1146/annurev.energy.23.1.253, March $16^{\text {th }}, 2014$

Gintz, D., Hassan, M. A., \& Schmidt, K.-H. (1996). Frequency and Magnitude of Bedload transport in a Mountain River. Earth Surface Processes and Landforms, 21, 433-445.

Gippel, C. J. (1995). Potential of turbidity monitoring for measuring the transport of suspended solids in streams. Hydrological Processes, 9(83-97).

Gomi, T., Moore, R., \& Hassan, M. (2005). Suspended sediment dynamics in small forest streams of the Pacific Northwest. JAWRA Journal of the American Water Resources Association, 2, 877-898.

Gregory, R. S., \& Northcote, T. G. (1993). Surface, Planktonic and Benthic Foraging by Juvenile Chinook Salmon (Onchorhynchus tshawytscha) in Turbid Laboratory Conditions. Canadian Journal of Fisheries and Aquatic Science, 50, 233-240.

Gruszowski, K. E., Foster, I. D. L., Lees, J. a., \& Charlesworth, S. M. (2003). Sediment sources and transport pathways in a rural catchment, Herefordshire, UK. Hydrological Processes, 17(13), 2665-2681. doi:10.1002/hyp.1296

Haggart, J. W. (2004). Geology, Queen Charlotte Islands, British Columbia. Geological Survey of Canada, Open File .

Hassan, M. A., Church, M., \& Ashworth, P. J. (1992). Virtual Rate and Mean Distance of Travel of Individual Clasts in Gravel bed Channels. Earth Surface Processes and Landforms, 17, $617-627$. 
Hassan, M. A., Church, M., Lisle, T. E., Brardinoni, F., Benda, L., \& Grant, G. E. (2005). Sediment transport and channel morphology of small, forested streams. Journal of the American Water Resources Association, 97331, 853-876.

Hassan, M. a., Church, M., Yan, Y., \& Slaymaker, O. (2010). Spatial and temporal variation of in-reach suspended sediment dynamics along the mainstem of Changjiang (Yangtze River), China. Water Resources Research, 46(11), 14 pp. doi:10.1029/2010WR009228

Hassan, M. a., Church, M., Yan, Y., Slaymaker, O., \& Xu, J. (2011). Suspended sediment balance for the mainstem of Changjiang (Yangtze River) in the period 1964-1985. Hydrological Processes, 25(15), 2339-2353. doi:10.1002/hyp.7996

Hassan, M. A., \& Ergenzinger, P. (2003). Use of Tracers in Fluvial Geomorphology. In Tools in Fluvial Geomorphology (p. Chapter 14).

Hassan, M. a., Robinson, S. V. J., Voepel, H., Lewis, J., \& Lisle, T. E. (2014). Modeling temporal trends in bedload transport in gravel-bed streams using hierarchical mixed-effects models. Geomorphology, 219, 260-269. doi:10.1016/j.geomorph.2014.05.019

Hassan, M. A., Schtick, A. P., \& Shaw, P. A. (1995). Movement of Pebbles on a sand bed river, Botswana. In Application of Tracers in Arid Zone Hydrology, IAHS (Publicatio., pp. 437442).

Health Canada. (203AD). Guidelines for Canadian Drinking Water Quality (p. 87). Ottawa.

Hudson, R. O. (2001). Storm-based sediment budgets in a partially harvested watershed in coastal British Columbia (p. TR-09).

Jordan, P. (2006). The use of sediment budget concepts to assess the impact on watersheds of forestry operations in the southern interior of British Columbia. Geomorphology, 79, $27-44$.

Junk, W., Bayley, P., \& Sparks, R. (1989). The flood pulse concept in river-floodplain systems. Canadian Special Publication of Fisheries and Aquatic Sciences, 106(1), 110-127. 
Kemp, P., Sear, D., Collins, A., Naden, P., \& Jones, I. (2011). The impacts of fine sediment on riverine fish. Hydrological Processes, 25(11), 1800-1821. doi:10.1002/hyp.7940

Kondolf, G. M. (2000). Assessing Salmonid Spawning Gravel Quality. Transactions of the American Fisheries Society, 129, 262-281.

Lambert, C. P., \& Walling, D. E. (1988). Measurement of channel storage of suspended sediment in a gravel bed river. Catena, 15, 65-80.

Lane, P. N. J., \& Sheridan, G. J. (2002). Impact of an unsealed forest road stream crossing: water quality and sediment sources. Hydrological Processes, 16(13), 2599-2612. doi:10.1002/hyp.1050

Langois, J. L., Johnson, D. W., \& Mehuys, G. R. (2005). Suspended sediment dynamics associated with snowmelt runoff in a small mountain stream of Lake Tahoe. Hydrological Processes, 19, 3569-3580.

Lawler, D. M. (1993). The measurement of river bank erosion and lateral channel change: A review. Earth Surface Processes and Landforms, 18(9), 777-821. doi:10.1002/esp.3290180905

Lehre, A. . (1982). Sediment budget of a small coast range drainage basin in Northern California. In Sediment Budgets and Routing in Forest Drainage Basins (pp. 67-77).

Lewis, J., \& Eads, R. (2001). Turbidity threshold sampling for suspended-sediment load estimation. In Proceedings of the seventh federal interagency sedimenation conference (pp. 110-117). Reno, N.V.

López-Tarazón, J. a., Batalla, R. J., Vericat, D., \& Francke, T. (2012). The sediment budget of a highly dynamic mesoscale catchment: The River Isábena. Geomorphology, 138(1), 15-28. doi:10.1016/j.geomorph.2011.08.020 
Luce, C. H., \& Black, T. a. (1999). Sediment production from forest roads in western Oregon. Water Resources Research, 35(8), 2561. doi:10.1029/1999WR900135

Marquis, P. (2005). Turbidity and Suspended Sediment as Measures of Water Quality, Streamline, 9(1), 21-23.

McDonald, L. (2001). Special issue runoff and road erosion at the plot and road segment scales, St John, US Virgin Islands. Earth Surface Processes and Landforms, 26, 251-272. Retrieved from

Mclean, D., Church, M., \& Tassone, B. (1999). Sediment Transport along Lower Fraser River 1: Measurements and Hydraulic Computations. Water Resources Research, 35(8), 2533-2548.

Megahan, W., \& Ketcheson, G. (1996). Predicting downslope travel of granitic sediments from forest roads in Idaho. JAWRA Journal of the American Water Resource Association, 32(2). doi/10.1111/j.1752-1688.1996.tb03459.x/abstract

Meidinger, D., \& Pojar, J. (1991). Ecosystems of British Columbia, Special report series 6. Victoria, B.C.

Moore, R. D., \& Wondzell, S. M. (2005). Physical hydrology and the effects of forest harvesting in the Pacific Northwest: a review. Journal of the American Water Resources Association, 763-784.

Moore, R., \& Wondzell, S. (2005). Physical hydrology and the effects of forest harvesting in the Pacific Northwest: a review. JAWRA Journal of the American Water Resources Association, 763-784. doi/10.1111/j.1752-1688.2005.tb03770.x/abstract

Motha, J. A., Wallbrink, P. J., Hairsine, P. B., \& Grayson, R. B. (2003). Determining the sources of suspended sediment in a forested catchment in southeast Australia. Water Resources Research, 39(3), 14 pp. 
Paustian, S., \& Beschta, R. L. (1979). The suspended sediment regime of an Oregon Coast range stream. JAWRA Journal of the American Water Resources Association, 15(1), 144-154.

Province of British Columbia. (2002). Forest Road Engineering Guidebook (p. 218). Victoria, B.C.

Ramos-Scharrón, C., \& Macdonald, L. (2007). Runoff and Suspended-sediment Yield from an Unpaved Forest Road Segment, St. John, U.S. Virgin Islands. Hydrological Processes, 21, $35-50$.

Reid, L., \& Dunne, T. (1984). Sediment production from forest road surfaces. Water Resources Research, 20(11), 1753-1761.

Reid, L., Dunne, T., \& Cederholm, C. (1981). Application of sediment budget studies to the evaluation of logging road impact. Journal of Hydrology, 49-62.

Roberts, R., \& Church, M. (1986). The sediment budget in severely disturbed watersheds, Queen Charlotte Range, British Columbia. Canadian Journal of Forest Research, 16, 1092-1106.

Rodgers, M., Hayes, G., \& Healy, M. G. (2009). Cyclic loading tests on sandstone and limestone shale aggregates used in unbound forest roads. Construction Building Materials, 23, 24212427.

Rood, K. M. (1984). An aerial photograph inventory of the frequency and yield of mass wasting on the Queen Charlotte Islands, British Columbia (p. 65pp). Victoria.

Sauer, V. ., \& Moyer, R. W. (1992). Determination of Error in Individual Discharge Measurements. U.S. Geological Survey, Open File Report 92-144, 21pp.

Schwab, J. (1998). Landslides on the Queen Charlotte Islands: Processes, Rates, and Climatic Events. In Carnation Creek and Queen Charlotte Islands Fish/Forestry Workshop: Applying 20 Years of Coastal Research to Management Solutions. (pp. 41-48). 
Sheridan, G. J., Noske, P. J., Whipp, R. K., \& Wijesinghe, N. (2006). The effect of truck traffic and road water content on sediment delivery from unpaved forest roads. Hydrological Processes, 20(8), 1683-1699. doi:10.1002/hyp.5966

Sheridan, G., \& Noske, P. (2007). A quantitative study of sediment delivery and stream pollution from different forest road types. Hydrological Processes, 21, 387-398. doi:10.1002/hyp

Sidle, R. C., \& Campbell, A. J. (1985). Patterns of suspended sediment transport in a Coastal Alaska Stream. Water Resources Bulletin, 21, 909-917.

Smith, B., Naden, P., Leeks, G., \& Wass, P. The influence of storm events on fine sediment transport, erosion and deposition within a reach of the River Swale, Yorkshire, UK. The Science of The Total Environment, 314-316(03), 451-474. doi:10.1016/S00489697(03)00068-8

Smith, B. P. G., Naden, P. S., Leeks, G. J. L., \& Wass, P. D. (n.d.). Characterising the fine sediment budget of a reach of the River Swale, Yorkshire, U . K . during the 1994 to 1995 winter season, 135-143.

Spinelli, R., \& Marchi, L. (1996). A literature review of the environmental impacts of forest road construction, paper presented at the seminar on environmentally sound forest roads and wood transport, Sinaia, Romania. In Seminar on environmentally sound forest roads and wood transport, Sinaia, Romania.

Taylor, J. (1997). Introduction to Error Analysis, the Study of Uncertainties in Physical Measurements, 2nd Edition. New York: University Science Books.

Uhrich, M., \& Bragg, H. (2003). Monitoring instream turbidity to estimate continuous suspended sediment loads and yields and clay-water volumes in the upper North Santiam River Basin, Oregon, 1998-2000 (p. 53). Portland, Oregon. 
Van Meerveld, H. J., Baird, E. J., \& Floyd, W. C. (2014). Controls on Sediment Production from an Unpaved Forest Road in a Pacific Maritime Watershed. Water Resources Research, 118. doi:10.1002/2013WR014605.Received

Walling, D. E., Collins, a. L., Jones, P. a., Leeks, G. J. L., \& Old, G. (2006). Establishing finegrained sediment budgets for the Pang and Lambourn LOCAR catchments, UK. Journal of Hydrology, 330(1-2), 126-141. doi:10.1016/j.jhydrol.2006.04.015

Webb, B. W., Phillips, J. M., Walling, D. E., Littlewoodb, I. G., Wattsb, C. D., \& Leeksb, G. J. L. (1997). Load estimation methodologies for British rivers and their relevance to the LOIS RACS ( R ) programme, 9697(96).

Whiting, P., \& Bradley, J. (1993). A process-based classification system for headwater streams. Earth Surface Processes and Landforms, 18(7), 603-612.

Wilde, F. D., \& Gibs, J. (1998). Handbook for water resources investigations - Section A. In National Field Manual for the Collection of Water Quality Data. Field measurements Turbidity (p. 30).

Wondzell, S., \& King, J. G. (2003). Post-fire erosional processes in the Pacific Northwest and Rocky Mountain Regions. Hydrological Processes, 178, 75-87.

Wood, P. J., \& Armitage, P. D. (1997). Biological Effects of Fine Sediment in the Lotic Environment. Environmental Management, 21, 203-217.

Ziegler, A. D., \& Giambelluca, T. W. (1997). Importance of Rural Roads as Sources of Sediment in Mountainous Areas of Northern Thailand. Geomorphology, 41(4), 249-262.

Ziegler, A., Sutherland, R., \& Giambelluca, T. (2001). Interstorm surface preparation and sediment detachment by vehicle traffic on unpaved mountain roads. Earth Surface Processes and Landforms, 26, 235-250. 